San Jose State University

SJSU ScholarWorks

Mineta Transportation Institute Publications

$1-2021$

\title{
Local Climate Action Planning as a Tool to Harness the Greenhouse Gas Emissions Mitigation and Equity Potential of Autonomous Vehicles and On-Demand Mobility
}

\author{
Serena Alexander \\ San Jose State University, serena.alexander@sjsu.edu \\ Asha Weinstein Agrawal \\ San Jose State University, asha.weinstein.agrawal@sjsu.edu \\ Benjamin Y. Clark \\ University of Oregon
}

Follow this and additional works at: https://scholarworks.sjsu.edu/mti_publications

Part of the Navigation, Guidance, Control, and Dynamics Commons, Sustainability Commons, and the Transportation Commons

\section{Recommended Citation}

Serena Alexander, Asha Weinstein Agrawal, and Benjamin Y. Clark. "Local Climate Action Planning as a Tool to Harness the Greenhouse Gas Emissions Mitigation and Equity Potential of Autonomous Vehicles and On-Demand Mobility" Mineta Transportation Institute Publications (2021). https://doi.org/10.31979/ mti.2020.1818

This Report is brought to you for free and open access by SJSU ScholarWorks. It has been accepted for inclusion in Mineta Transportation Institute Publications by an authorized administrator of SJSU ScholarWorks. For more information, please contact scholarworks@sjsu.edu. 


\section{SJSU UANJVSES STATI}

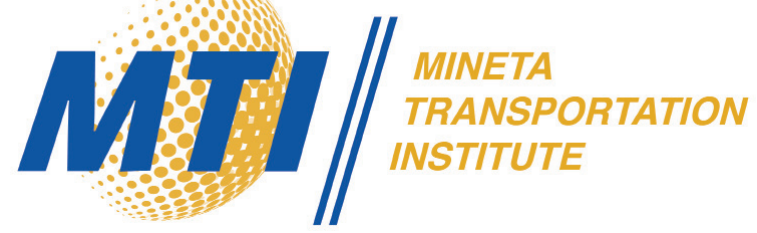

Local Climate Action Planning as a Tool to Harness the Greenhouse Gas Emissions Mitigation and Equity Potential of Autonomous Vehicles and On-Demand Mobility

Serena E. Alexander, $\mathrm{PhD}$

Asha Weinstein Agrawal, $\mathrm{PhD}$

Benjamin Y. Clark, PhD

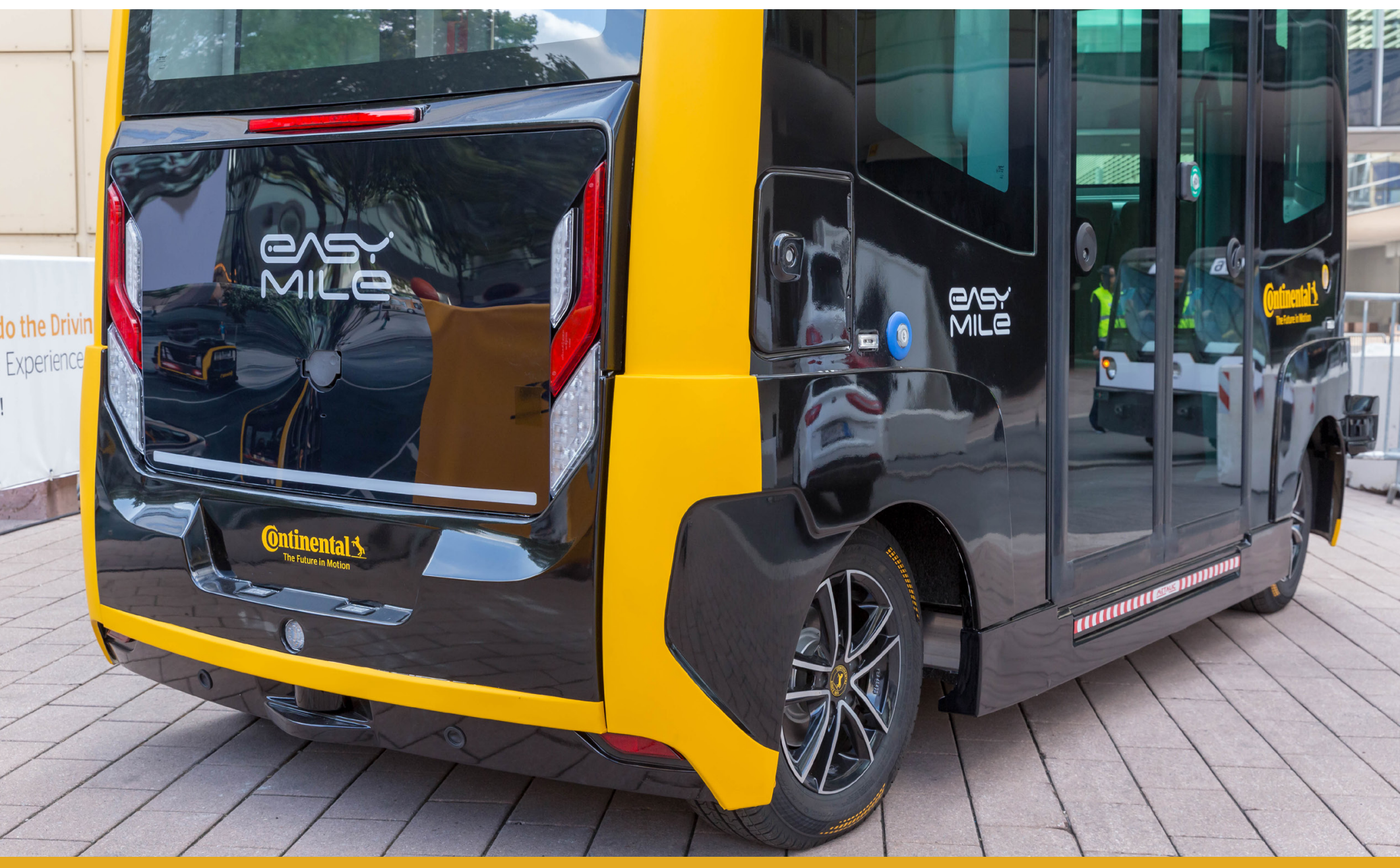




\section{Mineta Transportation Institute}

Founded in 1991, the Mineta Transportation Institute (MTI), an organized research and training unit in partnership with the Lucas College and Graduate School of Business at San José State University (SJSU), increases mobility for all by improving the safety, efficiency, accessibility, and convenience of our nation's transportation system. Through research, education, workforce development, and technology transfer, we help create a connected world. MTI leads the Mineta Consortium for Transportation Mobility (MCTM) funded by the U.S. Department of Transportation and the California State University Transportation Consortium (CSUTC) funded by the State of California through Senate Bill 1.

MTI focuses on three primary responsibilities:

\section{Research}

MTI conducts multi-disciplinary research focused on surface transportation that contributes to effective decision making. Research areas include: active transportation; planning and policy; security and counterterrorism; sustainable transportation and land use; transit and passenger rail; transportation engineering; transportation finance; transportation technology; and workforce and labor. MTI research publications undergo expert peer review to ensure the quality of the research.

\section{Education}

To ensure the efficient movement of people and products, we must prepare a new cohort of transportation professionals who are ready to lead a more diverse, inclusive, and equitable transportation industry. To help achieve this, MTI sponsors a suite of workforce development and education opportunities. The Institute supports educational programs offered by the Lucas Graduate School of Business: a Master of
Science in Transportation Management, plus graduate certificates that include High-Speed and Intercity Rail Management and Transportation Security Management. These flexible programs offer live online classes so that working transportation professionals can pursue an advanced degree regardless of their location.

\section{Information and Technology Transfer}

MTI utilizes a diverse array of dissemination methods and media to ensure research results reach those responsible for managing change. These methods include publication, seminars, workshops, websites, social media, webinars, and other technology transfer mechanisms. Additionally, MTI promotes the availability of completed research to professional organizations and works to integrate the research findings into the graduate education program. MTI's extensive collection of transportation-related publications is integrated into San José State University's world-class Martin Luther King, Jr. Library.

\section{Disclaimer}

The contents of this report reflect the views of the authors, who are responsible for the facts and accuracy of the information presented herein. This document is disseminated in the interest of information exchange. MTI's research is funded, partially or entirely, by grants from the California State University Office of the Chancellor, the California Department of Transportation, the U.S. Department of Homeland Security, and the U.S. Department of Transportation, who assume no liability for the contents or use thereof. This report does not constitute a standard specification, design standard, or regulation. 
Report 20-41

\section{Local Climate Action Planning as a Tool to Harness the Greenhouse Gas Emissions Mitigation and Equity Potential of Autonomous Vehicles and On-Demand Mobility}

Serena E. Alexander, $\mathrm{PhD}$ Asha Weinstein Agrawal, $\mathrm{PhD}$

Benjamin Y. Clark, PhD

January 2021

A publication of the Mineta Transportation Institute

Created by Congress in 1991 


\section{TECHNICAL REPORT DOCUMENTATION PAGE}

\begin{tabular}{|c|c|c|c|}
\hline $\begin{array}{l}\text { 1. Report No. } \\
20-41\end{array}$ & 2. Government Accession No. & \multicolumn{2}{|c|}{ 3. Recipient's Catalog No. } \\
\hline \multicolumn{2}{|l|}{ 4. Title and Subtitle } & \multicolumn{2}{|c|}{ 5. Report Date } \\
\hline \multicolumn{2}{|c|}{$\begin{array}{l}\text { Local Climate Action Planning as a Tool to Harness the Greenhouse Gas Emissions } \\
\text { Mitigation and Equity Potential of Autonomous Vehicles and On-Demand Mobility }\end{array}$} & \multicolumn{2}{|c|}{ 6. Performing Organization Code } \\
\hline \multicolumn{2}{|c|}{$\begin{array}{l}\text { 7. Authors } \\
\quad \text { Serena E Alexander. PhD: Asha Weinstein Aorawal. PhD. Beniamin Y Clark, PhD }\end{array}$} & \multicolumn{2}{|c|}{$\begin{array}{l}\text { 8. Performing Organization } \\
\text { Report } \\
\text { CA-MTI-1818 }\end{array}$} \\
\hline \multicolumn{2}{|l|}{ 9. Performing Organization Name and Address } & \multicolumn{2}{|c|}{ 10. Work Unit No. } \\
\hline \multicolumn{2}{|l|}{$\begin{array}{l}\text { Mineta Transportation Institute } \\
\text { College of Business } \\
\text { San José State University } \\
\text { San José, CA } 95192-0219\end{array}$} & \multicolumn{2}{|c|}{$\begin{array}{l}\text { 11. Contract or Grant No. } \\
\text { 69A } 3551747127\end{array}$} \\
\hline \multirow{2}{*}{\multicolumn{2}{|c|}{$\begin{array}{l}\text { 12. Sponsoring Agency Name and Address } \\
\text { U.S. Department of Transportation } \\
\text { Office of the Assistant Secretary for Research and Technology } \\
\text { University Transportation Centers Program } \\
1200 \text { New Jersey Avenue, SE } \\
\text { Washington, DC } 20590\end{array}$}} & \multicolumn{2}{|c|}{$\begin{array}{l}\text { 13. Type of Report and Period } \\
\text { Covered } \\
\text { Final Report }\end{array}$} \\
\hline & & \multicolumn{2}{|c|}{ 14. Sponsoring Agency Code } \\
\hline \multicolumn{4}{|l|}{$\begin{array}{l}\text { 15. Supplemental Notes } \\
\text { DOI: } 10.31979 / \mathrm{mti} .2020 .1818\end{array}$} \\
\hline \multicolumn{4}{|c|}{$\begin{array}{l}\text { This report focuses on how cities can use climate action plans (CAPs) to ensure that } \\
\text { vehicles (AVs) help reduce, rather than increase, green-house gas (GHG) emissio } \\
\text { transportation system. We employed a three-pronged research strategy involving: (1) } \\
\text { on-demand mobility and AVs; (2) a systematic content analysis of } 23 \text { CAPs and gen } \\
\text { in California; and (3) a comparison of findings from the literature and content analysi } \\
\text { GHG emissions reduction and mobility equity. }\end{array}$} \\
\hline \multicolumn{4}{|c|}{$\begin{array}{l}\text { Findings indicate that maximizing the environmental and social benefits of AVs and on-demand mobility requires proactive } \\
\text { and progressive planning; yet, most cities are lagging behind in this area. Although municipal CAPs and general plans in } \\
\text { California have adopted a few strategies and programs relevant to AVs and on-demand mobility, many untapped } \\
\text { opportunities exist to harness the GHG emissions reduction and social benefits potential of AVs and on-demand mobility. } \\
\text { Policy and planning discussions should consider the synergies between AVs and on-demand mobility as two emerging } \\
\text { mobility trends, as well as the key factors (e.g., vehicle electrification, fuel efficiency, use and ownership, access and } \\
\text { distribution, etc.) that determine whether deployment of AVs would help reduce GHG emissions from transportation. } \\
\text { Additionally, AVs and on-demand mobility can potentially contribute to a more equitable transportation system by } \\
\text { improving independence and quality of life for individuals with disabilities and the elderly, enhancing access to transit, and } \\
\text { helping alleviate the geographic gap in public transportation services. }\end{array}$} \\
\hline $\begin{array}{l}\text { 17. Key Words } \\
\text { Autonomous Vehicles, Climate Action } \\
\text { Planning, On-Demand Mobility, Shared } \\
\text { Mobility, Electric Vehicles, Greenhouse } \\
\text { Gas Emissions, Transportation Equity }\end{array}$ & $\begin{array}{l}\text { 18. Distribution Statement } \\
\text { No restrictions. This document is av: } \\
\text { National Technical Information Serv }\end{array}$ & $\begin{array}{l}\text { ble to the } p \\
\text { Springfiel }\end{array}$ & $\begin{array}{l}\text { through The } \\
\text { A } 22161\end{array}$ \\
\hline $\begin{array}{l}\text { 19. Security Classif. (of this report) } \\
\text { Unclassified }\end{array}$ & $\begin{array}{l}\text { 20. Security Classif. (of this page) } \\
\text { Unclassified }\end{array}$ & $\begin{array}{l}\text { 21. No. of } \\
\text { Pages } \\
\quad 68\end{array}$ & 22. Price \\
\hline
\end{tabular}

FORM DOT F 1700.7 (8-72) 
Copyright (C) 2021

\section{by Mineta Transportation Institute}

All rights reserved.

DOI: 10.31979/mti.2020.1818

Mineta Transportation Institute College of Business

San José State University San José, CA 95192-0219

Tel: (408) 924-7560

Fax: (408) 924-7565

Email: mineta-institute@sjsu.edu

transweb.sjsu.edu/research/1818 


\section{ACKNOWLEDGMENTS}

The authors thank the following people for their important contributions to this project:

- Research assistants Alverina E. Weinardy, Kally Yeung, and Ashley M. Hooper; and

- The MTI staff and anonymous reviewers.

Cover Photo: https://www.flickr.com/photos/160866001@N07/48752363953/in/photolist-UykSYC-UU5ZBu-UU5ZkhEJt6th-2hh7kSm-9o1FrD-2hh5Bic-qPTpog-dPKtnt-okV4hS-Ebex7W

License: https://creativecommons.org/licenses/by/2.0/ 


\section{CONTENTS}

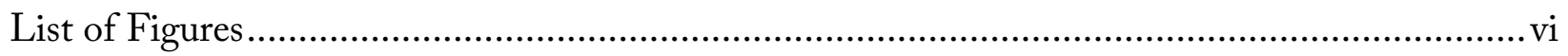

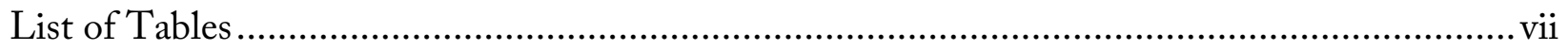

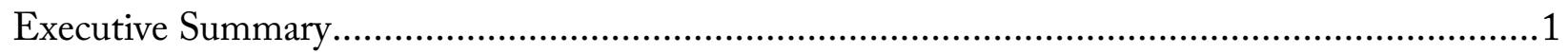

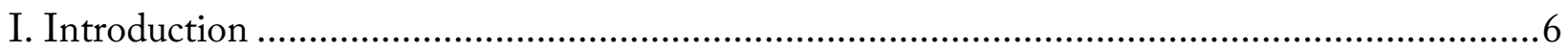

1.1 Potential Environmental and Social Impacts from AVs and

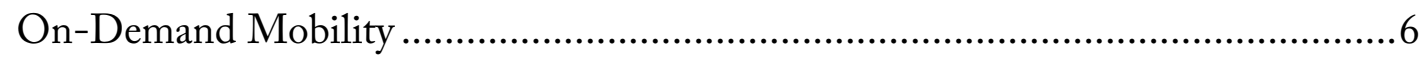

1.2 The Role for Climate Action Plans .....................................................................

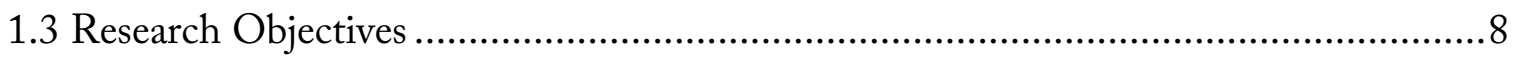

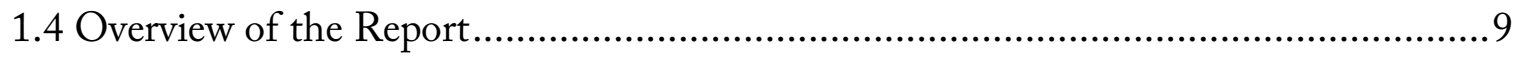

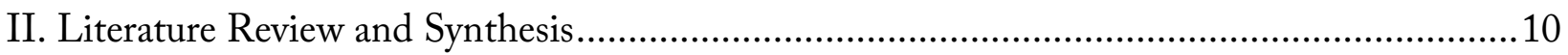

2.1 Concepts of Autonomous Vehicle and On-Demand Mobility Services .....................11

2.2 Summary of Findings about the Predicted Type and Range of Impacts ...................15

2.3 A Synthesis of Major Findings from the Literature.................................................17

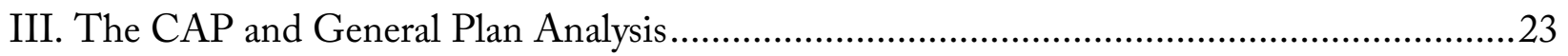

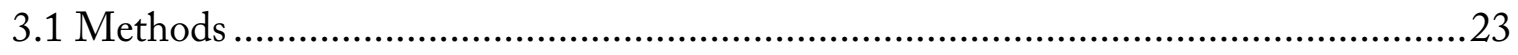

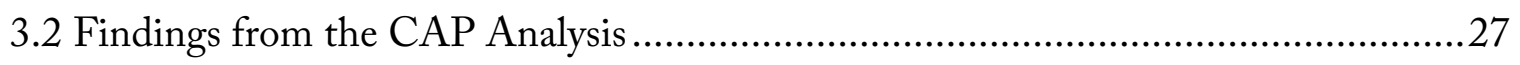

3.3 Findings from the General Plan Analysis..................................................................

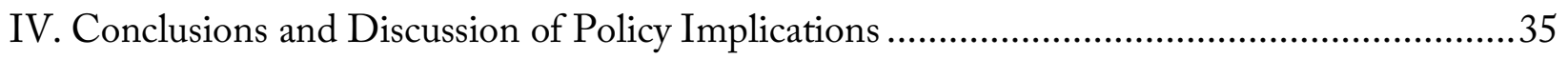

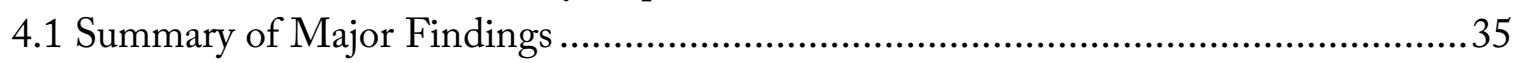

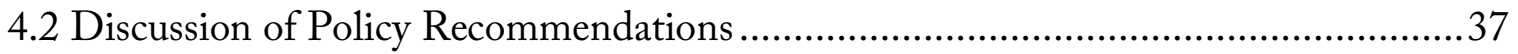

4.3 Study Limitations and Recommendations for Future Research ...............................40

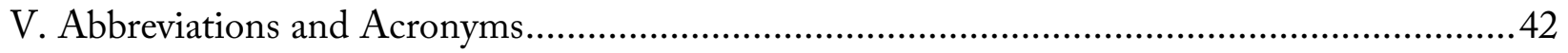

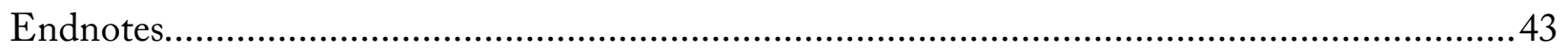

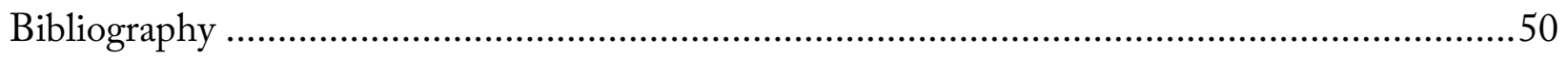

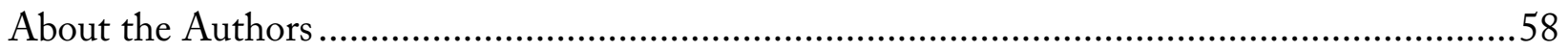




\section{LIST OF FIGURES}

Figure 1. SAE Levels of Driving Automation (SAE International 2018)................................12 


\section{LIST OF TABLES}

Table 1. Summary Assessment of GHG Emissions and Social Changes from the Literature ....16

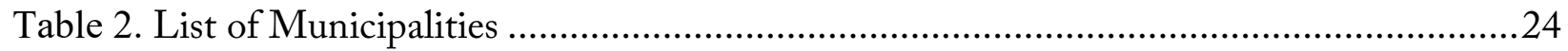

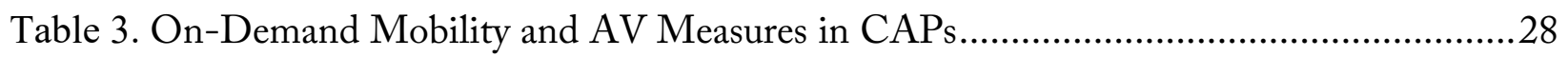

Table 4. On-Demand Mobility and AV Measures in General Plans .........................................32 


\section{Executive Summary}

\section{Introduction}

This report identifies opportunities for how cities can use climate action plans (CAPs) to ensure that on-demand mobility and autonomous vehicles (AVs) help reduce, rather than increase, greenhouse gas (GHG) emissions, vehicle miles traveled (VMT), and/or inequitable impacts from the transportation system. The overarching question answered by this report is: how can local governments in California use CAPs to harness the GHG emissions reduction and mobility equity potential of on-demand mobility and AVs?

CAPs are planning documents that propose a comprehensive set of programs and policies that the government entity can use to combat climate change, as well as to mitigate the social costs of its adverse impacts. Because the transportation sector generates such a large proportion of GHG emissions, CAPs by necessity include considerable content related to transportation. Additionally, local CAPs increasingly focus on enhancing social equity locally while also contributing to global climate justice through mitigation of GHGs. Thus, CAPs have the potential to serve as a key tool for local governments to harness the GHGs mitigation and mobility equity potential of ondemand mobility and AVs.

\section{Study Methods}

A three-pronged research strategy was employed to answer the research question involving: (1) an analysis of the current literature on on-demand mobility and AVs; (2) a systematic content analysis of 23 CAPs and general plans developed by municipalities in California; and (3) a crosscomparison of findings from the literature and content analysis of plans to identify opportunities for GHG emissions reduction and mobility equity through adoption of on-demand mobility and AVs.

We chose to analyze a set of cities that are well-known for being in the vanguard of climate planning. Studying these early actors in climate planning allowed us to focus on communities that are the most likely to have thought through and experienced the challenges of reducing transportation emissions significantly. Thus, these cities are particularly likely to have searched for new and innovative ways of successfully tackling GHGs from transportation.

We used a four-step process to analyze the CAPs and general plans. In Phase I, we developed a framework based on the literature to capture specific information about strategies to reduce transportation emissions along with general information such as GHG emissions targets and baseline emissions levels. In Phase II, we coded the CAPs and general plans using the framework developed in Phase I. Subsequently, in Phase III, we coded content pulled in the second phase to identify strategies and measures that were relevant to shared and/or on-demand mobility, ride- 
hailing, and AVs. Lastly, in Phase IV, findings from content analysis of plans were compared with findings from the literature to identify untapped opportunities and possible risks of AVs and ondemand mobility.

\section{Summary of Major Findings}

Analysis of the literature, municipal climate action plans (CAPs) and general plans yielded four major findings:

(1) Cities should consider synergies between autonomous vehicles (AVs) and on-demand mobility during policy and planning discussions about either one. The literature focusing on vehicle automation technologies overlaps with that of on-demand mobility. This is mainly because of the synergies between AVs and on-demand mobility that may help amplify adoption as well as benefits of both while reducing the risk of negative environmental or social impacts. For example, AVs can boost carsharing by eliminating the need for someone to travel to a carsharing facility to access available vehicles, and improving safety, and convenience. If $A V s$ are shared and used as a mobility service (as opposed to privately-owned single-occupancy vehicles), concerns about increased traffic, VMT, and consequently GHG emissions are significantly reduced. Shared AVs (or SAVs) are also more likely to be accessible to a wider range of users making their widespread and equitable adoption possible. Due to the synergies between AVs and on-demand mobility, any discussion of the maximization of benefits or minimization of risks should consider both of these emerging trends.

(2) Maximizing the environmental and social benefits of $A V s$ and on-demand mobility requires proactive and progressive planning; yet, most cities are lagging behind in this area. A comparison of findings from the literature and analysis of municipal CAPs and general plans shows that the environmental and social benefits of $\mathrm{AVs}$ and on-demand mobility will not be realized without a comprehensive strategic vision about what an ideal transportation system should look like, and what steps should communities take to get there. Nevertheless, one clear finding was that few cities were comprehensively planning to integrate AVs and on-demand mobility as tools to achieve climate and equity objectives. Close to one-third of the cities did not include any policy options related to on-demand mobility and AVs. And among the two-thirds of CAPs that did include relevant policy measures, few had more than a handful. Unsurprisingly, the CAPs that were developed or updated more recently were more likely to include policy measures related to shared and on-demand mobility and AVs. This reflects the importance of regularly updating CAPs to incorporate opportunities and challenges that new technologies present.

(3) Municipal CAPs and general plans in California have adopted several strategies and programs relevant to $A \boldsymbol{V}$ s and on-demand mobility. Since several of the commonly used TDM strategies, such as programs or policies to encourage carpooling, are applicable to AVs and on-demand mobility, the majority of municipal CAPs analyzed included at least a few relevant measures. Innovative measures adopted by recently updated CAPs involve measures to encourage TNCs to invest in electric vehicles; programs to promote "Mobility as a Service" (MaaS) through apps that offer 
seamless mobility payment and booking options; and partnerships with ride-hailing companies to connect nearby residents to public transit either free of charge or for a small fee.

As expected, municipal general plans were far less likely to include explicit interventions to ensure that AVs and on-demand mobility help communities reduce GHG emissions. The few plans that did include provisions for relevant emerging transportation technologies of interest, focused predominantly on bigger picture ideas, such as supporting research and development for AVs and other technological advances and planning for infrastructure investments and improvements.

(4) Several untapped opportunities exist to harness the GHG emissions reduction and social benefits potential of $A \boldsymbol{V}$ s and on-demand mobility. A comparison of findings from the literature review and analysis of municipal CAPs and general plans in California uncovers untapped opportunities to seize the GHG emissions reduction and social benefits of AVs and on-demand mobility. The following section details ways that CAPs can help communities plan for environmentally responsible and socially equitable adoption of $A V s$ and on-demand mobility.

\section{Conclusions and Policy Recommendations}

The study findings outlined above suggest seven specific ways that local governments can use CAPs to harness the GHG emissions mitigation and equity potential of on-demand mobility and AVs:

(1) Use CAPs as a tool to ensure equitable mobility in a driverless future. Since climate action planning and policy inventions are constantly engaging with the notion of just and equitable communities, existing or common measures utilized by CAPs can be strengthened to guide the equitable distribution and use of AVs and technology-enabled on-demand mobility. The recently updated CAPs more prominently acknowledge that effective climate action planning is rooted in social justice and equity. CAPs commonly stress the importance of protecting the most vulnerable, and prioritizing resources to address inherent inequities in our society, such as lack of access to safe, affordable and convenient public or active transportation options. Since AVs and on-demand mobility can either alleviate or exacerbate transportation equity gaps, CAPs should employ specific measures to maximize the potential benefits and minimize the risks. For example, CAPs can encourage or incentivize the use of shared AVs and on-demand mobility options as an affordable and convenient first- and last-mile solution.

(2) Provide comprehensive GHG emissions reduction roadmaps for AVs and on-demand mobility to reinforce general plan mobility goals. Although both municipal CAPs and general plans may include environmental measures relevant to $A V s$ and on-demand mobility, CAPs are more likely to provide detailed guidelines and innovative solutions specifically designed to combat climate change. As such, a GHG emissions reduction roadmap for AVs and on-demand mobility can be added to transportation demand management (TDM) strategies, as well as physical transportation 
infrastructure strategies, land-use policies, and regional coordination efforts highlighted in the CAPs. The CAP can then be linked to the general plan to reinforce its broader mobility goals.

(3) Encourage travelers to make a long-run shift to shared use of AVs and on-demand mobility. Analysis of the literature suggests that any claimed benefits of $A V s$ and on-demand mobility, such as reduced GHG emissions and traffic, will only be realized if these technologies make shared mobility more economical, convenient, and thus, more common or desirable. The widespread availability of app-enabled on-demand mobility options, dynamic geo-positioning technologies, and ease of electronic financial transactions, have cleared major hurdles of carpooling. Furthermore, AVs can help reduce or eliminate safety incidents, such as crashes and even assaults. Nevertheless, additional incentives might be required to shift the mobility preferences of individuals who always relied on private vehicles. More specifically, there is a need to redesign TDM strategies recommended by CAPs to encourage shared use of AVs and on-demand mobility and help shift mobility preferences of individuals towards shared mobility in the long-run.

(4) Use a combination of transportation and land-use policies to prevent increasing sprawl due to deployment of $A V$ s. Local CAPs typically recommend a variety of transportation and land-use strategies to combat sprawl, ranging from in-fill and transit-oriented development strategies to eliminating parking minimums. To ensure that the increased comfort and reduced value of travel time (due to the reduced opportunity cost of driving) associated with AVs will not inadvertently result in sprawl, local CAPs should utilize both transportation and land-use progressive policy options. Importantly, the combined effect of transportation and land-use policy options is often greater than the effect of one type of policy. This is because transportation and land-use policies work together in affecting travel behavior. For example, by eliminating parking minimums, CAPs can encourage shared use of $A V s$ as well as discouraging the private ownership of AVs. If most or all $A V s$ are shared and used as service on-demand, the need for parking space will further diminish resulting in an in-fill development opportunity.

(5) Stress the importance of energy efficiency and renewable energy in a driverless future. The biggest motivation for the development and deployment of $\mathrm{AVs}$ is increased safety and convenience-a robot will replace the driver, and it will follow all traffic rules and cannot be distracted. Other potential advantages of AVs, such as reduced GHG emissions, are considered co-benefits. These co-benefits are not necessarily guaranteed by manufacturers. Manufacturers might actually be tempted to build larger vehicles that can serve other purposes, such as an office, a gym, or a movie theater. These larger vehicles can be even more energy consumptive than the current singlepurpose vehicles. Local CAPs can help develop and adopt specific policies to ensure that AVs are energy efficient and/or electric.

(6) Identify opportunities to link AVs and on-demand mobility to transit. One major challenge associated with widespread deployment of $A V_{s}$ is the potential for declined transit ridership, decrease in public transportation funding, and eventually reduced options for the ones who do not have access to a car. The alternative scenario is that AVs and on-demand mobility options will be 
used to augment and complement public transportation. CAPs typically offer a variety of options to enhance the viability of public and active modes of transportation. CAPs also include first- and last-mile solutions to boost transit ridership. A combination of these strategies can be specifically designed to utilize the opportunities offered by AVs and app-enabled on-demand mobility options to connect individuals to transit stations easily or fill the mobility gaps in areas with limited or nonexistent transit options.

(7) Incorporate planning tools that respond to the uncertainty related to deployment of AVs and extensive use of on-demand mobility technologies. Since climate change poses many uncertainties, CAPs have long considered sophisticated and dynamic methods to deal with uncertainties, such as scenario analysis. CAPs have also acknowledged that uncertainties can discourage action, and thus recommended techniques to help stay focused on the desirable goals or outcomes. These common methods of dealing with uncertainties through CAPs can be used to help local governments envision a desirable mobility outcome in a driverless future and ensure that deployment of AVs and more extensive use of on-demand mobility will help us reduce GHG emissions as well as improve mobility for all. 


\section{Introduction}

This report identifies opportunities for how cities can use climate action plans (CAPs) to ensure that on-demand mobility and autonomous vehicles (AVs) help reduce, rather than increase, greenhouse gas (GHG) emissions, vehicle miles traveled (VMT), and/or inequitable impacts from the transportation system. The overarching question answered by this report is: how can local governments in California use CAPs to harness the GHG emissions reduction and mobility equity potential of on-demand mobility and AVs?

A three-pronged research strategy was employed to answer the research question involving: (1) a thorough analysis of the current literature on on-demand mobility and AVs; (2) a systematic content analysis of 23 CAPs and general plans developed by municipalities in California; and (3) a cross-comparison of findings from the literature and content analysis of plans to identify opportunities for GHG emissions reduction and mobility equity through adoption of on-demand mobility and AVs.

By offering strategies to integrate AVs and on-demand mobility into local CAPs, this research can help local governments in California and elsewhere take a more holistic approach to transportation planning that aligns with multiple environmental and social equity goals. Local CAPs are an ideal candidate for a comprehensive approach since these plans typically go beyond emissions reductions and involve discussions of social equity and community wellbeing. Technological advancements of $A V s$ and on-demand mobility can enhance the transportation emissions reduction potential of CAPs, and simultaneously contribute to social equity and quality of life. As such, this report opens a dialogue between local governments, $A V$ and on-demand mobility companies, and users of these technologies that can lead to better social and environmental outcomes.

\subsection{Potential Environmental and Social Impacts From AVs and On-Demand Mobility}

Two emerging trends in mobility-Autonomous Vehicles (AVs) and on-demand mobility (which includes ride-sharing and ride-hailing) — have the potential to dramatically impact travel behavior and, by extension, the environmental and social impacts of transportation. Examples of benefits associated with these two trends include better road utilization; increased safety for pedestrians and passengers; reduced traffic; increased in road capacity; enhanced access to jobs, services, and amenities for low-mobility individuals; reduced parking needs; improved equity; and reduced energy consumption. ${ }^{1}$ Nevertheless, these technologies also carry risks and, under certain scenarios, may even exacerbate, as opposed to relieve, mobility problems such as increased Vehicle Miles Travelled (VMT), ${ }^{2}$ high cost of transportation, and diminished support for public transportation investments. ${ }^{3}$ Additionally, it has been argued that there are other potential trade-offs, where GHG emissions from $A V$ production is expected to be higher than internal combustion vehicles, 
but the lifecycle costs have a lower net GHG cost to the environment. ${ }^{4}$ Thus, to maximize the benefits and minimize the risks, these technological developments should be accompanied by a holistic vision of vehicle life cycles, ${ }^{5}$ greater interoperability among transportation services, and stronger policy support for shared and low-carbon mobility. ${ }^{6}$

Recent literature emphasizes the potential energy and GHG impacts of vehicle automation and technology-enabled on-demand mobility and offers detailed scenario analysis to estimate such impacts. For example, researchers have estimated that AVs can result in up to an $80 \%$ energy-use reduction and up to a $94 \%$ reduction in $\mathrm{CO}_{2}$ through various mechanisms, such as platooning technologies, more efficient routing, more eco-friendly acceleration/braking, vehicle design, alternative fuel use, more efficient traffic flow, reduced parking needs, light-weight or efficient vehicles, and real-time or dynamic ridesharing. ${ }^{7}$ On-demand mobility technology has already shown promise of reducing GHG emissions. For example, empirical studies have shown that ondemand mobility can significantly reduce emissions compared to traditional taxis, which have emissions of up to 1.4 times higher compared to on-demand mobility. ${ }^{8}$ However, such emission reductions are not assured, and outcomes depend on how automation and on-demand mobility might impact travel behavior, vehicle operations, vehicle design, and the entire transportation system. Ironically, VMT and fuel consumption might significantly increase if the energy efficiency benefits of AVs are not realized. ${ }^{9}$ Also, if people can convert their commuting time to productive time, then they may choose to live further from high job concentration areas where housing is expensive. This could potentially increase VMT and GHG emissions. Therefore, it is critical to seize the energy and emissions mitigation opportunities of these technologies and minimize the risk of counterproductive outcomes through long-range policies and plans that offer a comprehensive vision of future mobility.

\subsection{The Role for Climate Action Plans}

CAPs are strategic documents that propose a comprehensive agenda to reduce GHG emissions and help communities adapt to the adverse impacts of climate change. The main question that these plans focus on is how cities can thrive in an environmentally and socially responsible way in a world threatened by climate change. CAPs typically include a list of strategies to mitigate GHG emissions from various sources, such as: transportation and land-use; energy supply; energy demand in residential, commercial and industrial buildings; agriculture; forestry; and waste. For example, constructing new and improved bicycle paths is a common strategy to reduce emissions from the transportation sector. CAPs may also offer several adaptation strategies that are designed to boost the ability of communities to withstand and recover from adverse climate impacts.

Local CAPs are in an ideal position to help unlock the environmental and mobility equity promises of $\mathrm{AVs}$ and on-demand mobility. CAPs can incorporate strategies to ensure that the GHG emissions reduction potential of $\mathrm{AVs}$ and on-demand mobility are realized. Also, understanding the extent to which the benefits of AVs and on-demand mobility align with CAP goals can help cities develop a better response to climate change while achieving other co-benefits, such as better 
connectivity, improved mobility for all, and walkability. Additionally, local CAPs increasingly focus on enhancing social equity locally while also contributing to global climate justice through the mitigation of GHGs. ${ }^{10}$ As such, the potential mobility equity benefits of AVs and on-demand mobility are highly relevant to CAP goals.

Of the four basic approaches to reduce transportation GHGs (vehicle technology, fuel technology, vehicle and systems operations, and travel activity), ${ }^{11}$ local CAPs have mostly focused on the latter two, since the first two are heavily influenced by federal and state policy and funding. ${ }^{12}$ However, recent advancements in vehicle technology and specially automation can dramatically impact travel activity. This makes vehicle technology strategies much more relevant to local CAPs. Because these technologies are relatively new and progressing rapidly, we anticipated that most local CAPs would lag behind in incorporating AVs and on-demand mobility. Thus, this research helps identify untapped opportunities in our current generation of local CAPs which can be used for future updates of these plans.

Despite the significance of incorporating potential impacts of $A V s$ and on-demand mobility in CAPs, it is unclear how these plans can benefit from such emissions reduction impacts. A review of long-range transportation plans revealed that uncertainties involved in these new technologies and their impacts on investment decisions have resulted in an elimination of AV discussions in virtually all long-range transportation plans. ${ }^{13}$ On the other hand, to meet California's long-term GHG emissions reduction goal (i.e., 80\% below 1990 levels by 2050), it is crucial to combine technological advancements and policy packages to mitigate emissions from transportation-the largest source of overall GHGs. This research addresses this gap in the literature by identifying ways to incorporate potential impacts of AVs and on-demand mobility into local CAPs.

\subsection{Research Objectives}

The main objectives of this report are threefold:

(1) Identify potential environmental as well as social benefits and risks of AVs and ondemand mobility through a thorough analysis of current literature:

Our assessment of the current literature uncovered potential opportunities and threats that may arise due to the adoption of $A V s$ and on-demand mobility that would help-or hinder-local governments to achieve their GHG emissions reduction and social equity goals.

(2) Examine the extent to which municipal planning efforts in California have considered potential benefits and risks of AVs and on-demand mobility:

A systematic content analysis of municipal CAPs and general plans was conducted in order to understand what efforts are currently being taken by municipalities in California to seize 
the potential GHG emissions reductions and social benefits of $A V s$ and on-demand mobility.

(3) Develop innovative planning approaches and policy interventions to ensure that AVs and on-demand mobility help communities achieve GHG emissions reduction and other potential social benefits from these technologies:

Reaching California's ambitious GHG emissions reduction target requires a better understanding of how technological and policy approaches can be combined for better results. By analyzing local CAPs and general plans as well as the literature, the research team developed innovative approaches that can be used by cities across the nation and beyond.

\subsection{Overview of the Report}

Chapter II offers a thorough analysis and synthesis of current literature on on-demand mobility and AVs. Because the literature on environmental and social impacts of AVs frequently overlaps with that of on-demand mobility, a combined analysis of both literatures has been provided. Chapter III offers a detailed explanation of the methods followed to analyze CAPs and general plans from 23 California cities, and describes findings from the analysis of CAPs and general plans respectively. Chapter IV concludes the report with a summary of key findings, a discussion of the policy implications that flow from those findings, and an assessment of the study limitations paired with suggestions for future research. 


\section{Literature Review and Synthesis}

This chapter presents findings from a review of research into the extent to which AVs and ondemand mobility may help—or hinder-local governments to achieve their GHG reduction and social equity goals.

To identify the relevant literature, we thoroughly searched databases and websites that capture both academic and professional material, including peer-reviewed articles, book chapters, dissertations, conference proceedings, white papers, and professional reports. Specific databases and websites consulted include Web of Science, ScienceDirect, TRID, Google Scholar, ABI/INFORM, Ingenta, JSTOR Journals and Books, ProQuest Dissertations and Theses, Shared-use Mobility Center, Innovative Mobility Research, and The Nexus Clearinghouse (University of Oregon).

The team used a variety of keyword search terms and combinations of these keywords to identify the relevant literature, including: autonomous vehicles (AV), shared autonomous vehicles (SAV), shared mobility, ride-hailing, transportation network companies (TNC), car-sharing, ridesharing, carpooling, vanpooling, low-carbon mobility, on-demand mobility, intelligent transportation systems, $A V s$ and equity, $A V s$ and social impact, $A V s$ and emissions, $A V s$ and projection, $A V s$ and climate action planning, etc. This process resulted in 75 relevant materials to review.

The 75 relevant documents identified were systematically coded according to themes developed through a mix of inductive and deductive analysis. One set of codes related to the theme of the specific categories of AVs and on-demand mobility mentioned in the documents. For example, some materials primarily focused on AVs, whereas others emphasized on-demand or shared mobility. A second group of codes related to the benefits and risks of deploying AVs and ondemand mobility. A third set of codes related to the theme of determinants of environmental and social risks and benefits associated with AVs and on-demand mobility.

Chapter II is organized into three sections. The next section focuses on common concepts or terms used to describe AV and on-demand mobility services. The second section discusses overall findings about the predicted type and range of impacts. The third section presents four major findings about the policy choices that are most likely necessary if communities are to realize the potential benefits and minimize the negative outcomes of $A V s$ and on-demand mobility. 


\subsection{Concepts of Autonomous Vehicle and On-Demand Mobility Services}

During the analysis of the literature, the research team identified 12 terms regularly used to describe specific types of AV services and on-demand mobility. These terms were used as keywords to search for relevant literature as well as to guide the content analysis of CAPs and general plans. Some of the terms explained below are directly related to AVs and app-enabled on-demand mobility, such as shared autonomous vehicles (SAVs); others are broader, such as carsharing. These 12 terms were later used to identify categories in CAPs and general plans that were appropriate for adding measures to improve the environmental and equity benefits of AVs and ondemand mobility. For example, programs to encourage carsharing can be used to boost the desirability and popularity of SAVs. Hence, the inclusion of these broader concepts in this report is justified.

It is important to note that the 12 terms, described below, are not mutually exclusive. Instead, many of these concepts are closely related or overlap. For example, transportation network companies (TNCs) provide ride-hailing services, and SAVs are often compared to a driverless Uber ride. The identification and inclusion of these terms are key to capturing relevant information both in the literature and in the CAPs and general plans. It is not uncommon for the plans or scholarly articles to discuss one or more of these concepts or use them interchangeably.

The 12 terms for the concepts of AVs and on-demand mobility are reflected in items (1) through (12) below.

(1) Connected and Autonomous Vehicles

Any vehicle that involves some level of technology to automate the act of human driving is considered an autonomous vehicle (AV). Since technology that allows vehicles to connect to other vehicles on the road is rapidly increasing, it is widely assumed that all AVs will also be connected vehicles, thereby improving the safety advantage of $\mathrm{AV}$ driven vehicles.

The SAE levels of driving automation (as shown in Figure 1) define the six levels of driving automation, from no automation to full automation. Figure 1 describes the stages by which vehicles will move towards complete automation. Policies that are being developed around AVs do not typically deal with levels $0-2$ on the SAE scale, but rather 3-5, i.e., the instances in which the car is driving itself. The Tesla autopilot feature is a level $3 \mathrm{AV}$ when engaged, but typically only operates on highways; thus, many cities do not have policies specifically centered on those Tesla vehicles. When level 5 automation is reached, we expect to have "the greatest potential to impact shared modes and pooled services" which will yield the most GHG emission reduction benefits. ${ }^{14}$ 
Figure 1. SAE Levels of Driving Automation (SAE International 2018)

\section{SAE J3016 ${ }^{\text {TM }}$ LEVELS OF DRIVING AUTOMATION}

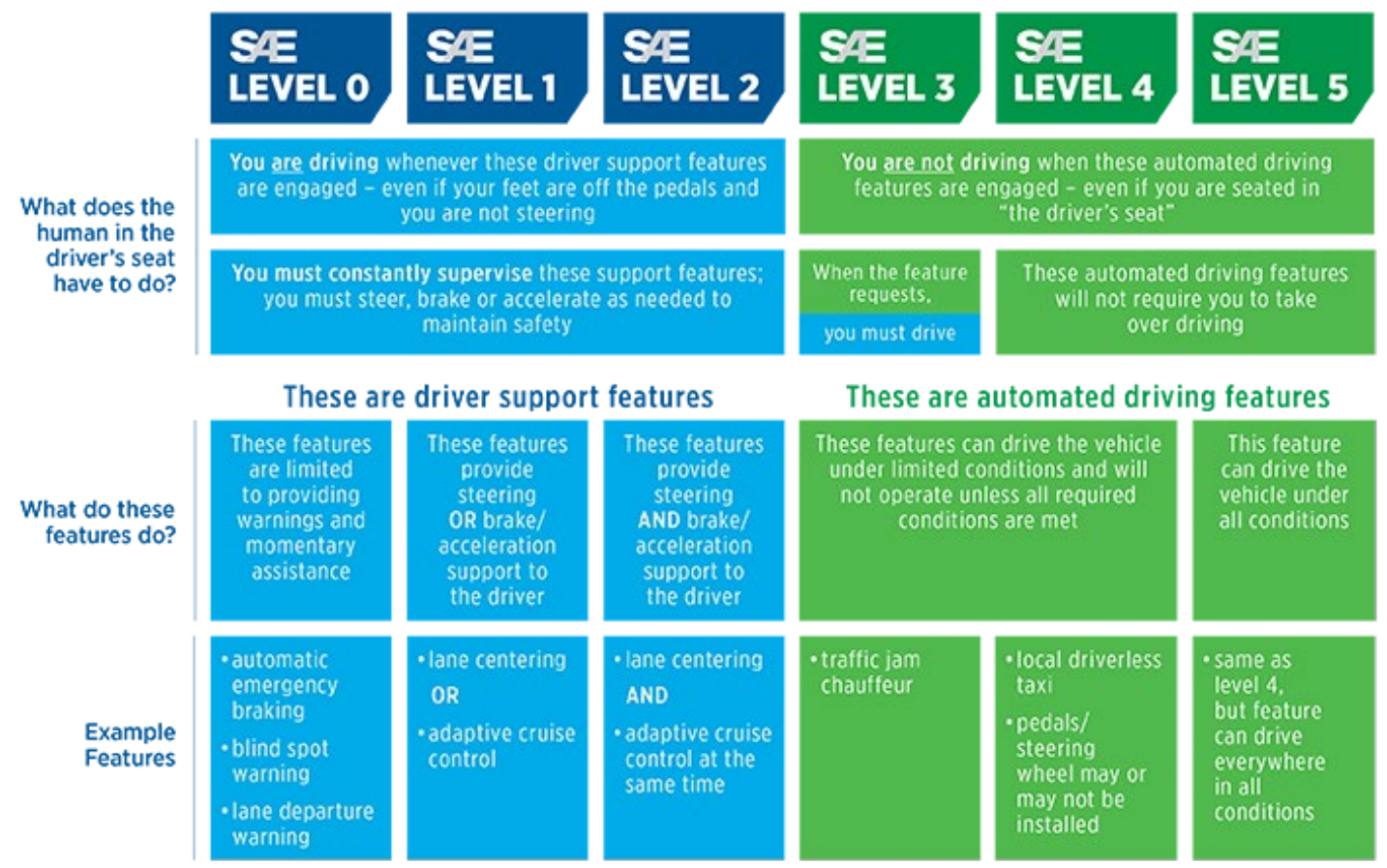

Connected vehicles are able to communicate with each other and infrastructure in different ways. These include:

- V2I, Vehicle to Infrastructure

- V2V, Vehicle to Vehicle

- V2C, Vehicle to Cloud

- V2P, Vehicle to Pedestrian

- V2X, Vehicle to Everything. ${ }^{15}$

(2) Shared Autonomous Vehicles

A shared AV is often compared to what Uber Pool as a service offers us today, a ride in a car with other people we do not know but are all headed in a similar direction-except, in the case of the $\mathrm{SAV}$, there is no driver. 
According to Urbanism Next, "Mobility as a service (MaaS) is a term used to describe both the idea that we purchase transportation as rides rather than as commodities-such as owning our own cars — as well as the online platforms that combine these ride options into a singular experience." 16 This means that public transportation and Uber are both considered MaaS providers. Lime or Bird scooters would also be considered MaaS providers. Sochor et al.'s typology helps to demonstrate the depth of integration across levels $0-4$, in which 0 indicates no integration, 1 means integration of information, 2 involves integration of booking and payment, 3 involves integration of the service offer, including contracts and responsibilities, and 4 includes integration of societal goals. ${ }^{17} \mathrm{~A}$ Google Map that shows bus routes and times would be considered level 1, as would Uber's integration of Denver Regional Transit's bus and train costs and routes in the Uber app. While first- and last-mile integration of ride-hailing into public transit systems would likely be considered a level 3 under most circumstances. ${ }^{18}$

\section{(4) Shared Mobility or Shared-Use Mobility}

Shared mobility is a broad term used to describe vehicles or travel devices that users rent for shortterm use. A diverse set of modes are shared, including private vehicles, bicycles, and electric scooters.

\section{(5) Transportation Network Companies (TNCs)}

TNCs are companies like Uber and Lyft that utilize an online application to provide an arranged transportation service for a fee by connecting passengers with drivers or car owners. Unlike a taxi service that can be hailed on a street without the use of a mobile app, passengers that wish to order a ride offered by a TNC should have access to the online application (for example, through a mobile app). TNCs typically use dynamic pricing models which means that prices for the same route might vary depending on supply and demand for rides at the time and location it is requested.

(6) Ride-Hailing (also called ride-sourcing or e-hailing)

Ride-hailing services, such as transportation services offered by TNCs, are not the same as traditional carpooling/ridesharing. Ride-hailing services are often used by individual riders or by groups of passengers that were already traveling together. Currently, many TNCs offer pooled ride-hailing, which can be considered true ridesharing. ${ }^{19}$ UberPool is the commercial service provided by Uber that fits this model of pooled ride-hailing.

\section{(7) Car-Sharing}

"Carsharing is an automobile-rental service intended as a substitute for private-vehicle ownership. Carsharing emphasizes affordability and convenience. Vehicles are located near residences, rented 
by the hour, and require minimal effort to check in and check out." ${ }^{20}$ The most popular carsharing service in the United States is ZipCar, though other firms, including car rental giants such as Hertz and Enterprise, also offer carsharing services in select cities. Car-sharing services also provide inneighborhood car rentals. These services, Zipcar and Getaround being two examples, allow users to pick up the vehicles nearby and drop them at the same or different location without going to a rental counter.

(8) Mobility on Demand/On-Demand Mobility

The term mobility on demand is a broader term to describe a number of new innovative ways in which people are using transportation today. This term is multi-modal in nature and may include a vehicle, bicycle, scooter, or any other transportation mode on an as-needed basis. Lyft, for example, now allows users to reserve bikes or scooters, as well as book a ride-hailing trip, all from the same online platform or app. In some cities, the app can also be used to book and pay for public transit trips. ${ }^{21}$

\section{(9) Ride-Sharing}

Ride-sharing includes the more traditional forms of sharing rides, such as carpooling or vanpooling. By definition, ridesharing is a way to increase or ideally maximize vehicle occupancy by allowing additional riders to join an existing trip. ${ }^{22}$ By contrast, a single passenger that orders an Uber ride is generating a new trip without necessarily sharing the ride with other passengers that are headed in a similar direction.

(10) Carpooling

Carpooling is "pre-arranged groups of people traveling from similar origins along similar routes or to similar destinations." 23

(11) Vanpooling

Vanpooling is described as "a group of five or more who share their commute in a van, either run by a private company or a local transit agency. The van takes you from a prearranged meeting place to work, school or other destinations." 24

\section{(12) Microtransit}

Microtransit refers to private multi-passenger transportation services, such as Bridj, Chariot, Split, and Via, that utilize dynamically-generated routes and typically expect riders to get to pick-up or drop-off locations on their own. Microtransit vehicles can be larger SUVs, vans, or shuttle buses. ${ }^{25}$ 


\subsection{Summary of Findings about the Predicted Type and Range of Impacts}

Overall, slightly more than half of the articles found by the research team focused on AVs or SAVs. One-quarter of the articles dealt with ride-sharing, carpooling, and vanpooling. About one-third of these articles address ride-hailing or transportation network companies (TNCs). And slightly more than a tenth of these articles address car-sharing programs. The literature in new mobility and autonomous vehicles is rapidly evolving, and consequently the current search of the literature is just a snapshot in time.

To predict the environmental and social benefits and/or risks of $A V s$ and on-demand mobility, most scholars utilized computer simulations and statistical or GIS modeling. While computer simulations and statistical models are appropriate techniques to analyze various scenarios, the range of potential outcomes is highly sensitive to the assumptions that are used in the model. For example, the GHG emissions outcomes (as well as social impacts) of AVs that are shared and electric would be very different from privately-owned AVs that are not energy efficient. This can result in vastly different projections for the environmental as well as social impacts of AVs and ondemand mobility. Nevertheless, by comparing these assumptions, one can develop a list of factors that are important for realizing the environmental and social benefits of $A V s$ and on-demand mobility. The four major findings presented in the last section of this chapter are a result of such analysis.

Table 1 shows the wide range of GHG emissions and social equity impacts of AVs and on-demand or shared mobility as predicted in the literature. 
Table 1. Summary Assessment of GHG Emissions and Social Changes from the Literature

\begin{tabular}{|c|c|c|c|c|}
\hline & GHG Emissions & Social Equity & Methods & Source(s) \\
\hline $\begin{array}{l}\text { Shared } \\
\text { Autonomous } \\
\text { Vehicles (SAVs) }\end{array}$ & $\begin{array}{l}\text { Increase in GHG as high as a 35\% (Stogios et al. } \\
\text { 2019) if not shared or empty (Zhang et al. 2018). } \\
\text { SAVs may decrease GHG by } 40 \% \text { (Tirachini 2019) } \\
\text { to up to } 97 \% \text { (Axsen and Sovacool 2019). Much of } \\
\text { GHG reductions will come from fleet } \\
\text { electrification ( } 60 \% \text { reduction), and up to } 87 \% \\
\text { when also include power source, ridesharing, vehicle } \\
\text { life, and computing power (Gawron et al. 2019). }\end{array}$ & $\begin{array}{l}\text { May increase exposure to advertising by } \\
\text { corporate ownership of transportation fleet, } \\
\text { and decrease pleasure in transit (Ferdman } \\
\text { 2020). Without proactive planning, SAVs } \\
\text { may diminish the sustainability of public } \\
\text { transportation (Creger et al. 2019). }\end{array}$ & $\begin{array}{l}\text { Primarily } \\
\text { computer } \\
\text { simulations and } \\
\text { statistical } \\
\text { modeling. }\end{array}$ & $\begin{array}{l}\text { Brown et al. 2014; Morrow et } \\
\text { al. 2014; National Research } \\
\text { Council, 2013; Kopelias et al. } \\
\text { 2020; Urban Land Institute } \\
\text { 2009; Gawron et al. 2019; } \\
\text { Stogios et al. 2019; Zhang et } \\
\text { al. 2018; Tirachini 2019; } \\
\text { Creger et al. 2019; Ferdman } \\
\text { 2020. }\end{array}$ \\
\hline $\begin{array}{l}\text { Transportation } \\
\text { Network } \\
\text { Companies (TNCs) } \\
\text { and Ride-Hailing }\end{array}$ & & $\begin{array}{l}\text { Electrification will have a faster payback of } \\
\text { higher vehicle cost for TNC drivers than for } \\
\text { EVs that are just for personal use- up to } 2 \text { to } \\
3 \text { times faster (Pavlenko 2019). TNCs can } \\
\text { provide access to transportation options in } \\
\text { areas without adequate public transit or taxi } \\
\text { coverage (Brown, 2019). }\end{array}$ & $\begin{array}{l}\text { GIS and } \\
\text { statistical } \\
\text { modeling. }\end{array}$ & Pavlenko 2019; Brown 2019. \\
\hline Car-Sharing & $\begin{array}{l}\text { Lower GHG in part by having more "owners" for } \\
\text { each car. Cars are closer to users than traditional car } \\
\text { rentals, thus less GHG intensive to obtain. } \\
\text { Carshare also tends to be complementary with } \\
\text { active and public transit, thus encourages lower- } \\
\text { GHG emitting transportation. }\end{array}$ & $\begin{array}{l}\text { May not flourish in areas that are not dense } \\
\text { (Shaheen et al. 2012). Per mile cost is higher } \\
\text { than owning a car-up to five times higher } \\
\text { and three times higher than public transit } \\
\text { (Litman 2000). Yet, carshare allows for } \\
\text { scalable 'ownership' of a car, thus providing } \\
\text { private travel to people who otherwise would } \\
\text { not be able to afford a vehicle. }\end{array}$ & & $\begin{array}{l}\text { Shaheen et al. 2012; Litman } \\
2000 .\end{array}$ \\
\hline Ride-Sharing & & $\begin{array}{l}\text { Social change will be required for higher } \\
\text { uptake of shared rides beyond traditional } \\
\text { carpooling and vanpooling. Success of } \\
\text { UberPool and similar services hints at how } \\
\text { this change may happen—and could reduce } \\
\text { vehicle traffic hours by } 22 \% \text {, and } \\
\text { consequently reduce GHG (Tirachini 2019). }\end{array}$ & $\begin{array}{l}\text { Statistical } \\
\text { analysis and } \\
\text { modeling. }\end{array}$ & Tirachini 2019. \\
\hline
\end{tabular}




\subsection{A Synthesis of Major Findings from the Literature}

A synthesis of the literature yielded four major findings related to policy choices that should be considered to harness the GHG emissions reduction and social benefits of AVs and on-demand mobility. A more detailed policy recommendations toolkit is offered in Chapter IV, which is based on findings from all phases of this research. Findings from the analysis and synthesis of the literature are the following:

- To ensure significant GHG emissions reduction, AVs should be shared and electric.

An analysis of the current literature on $A V$ s reveals that many factors can contribute to their overall GHG emissions impact. Typically, the literatures cites three types of factors impacting the GHG emissions contributions of AVs: (1) factors related to the technology, functionality and efficiency of AVs (e.g., vehicle electrification, fuel efficiency, size, connectedness, etc.); (2) factors related to the use and ownership of AVs (e.g., shared vs. single occupant; publicly-owned vs. privately-owned vehicles); and (3) factors related to access, distribution, and convenience of use of AVs across geography and for various population groups (e.g., wide or limited distribution of AVs in urban and suburban areas). Consequently, analysts have developed an extremely wide range of expected GHG emissions outcomes because of the uncertainty surrounding AVs. As an example, Greenblatt and Shaheen's (2015) report estimate of AV energy use and GHG emissions ranges from an 80 percent or greater decrease to a threefold increase. ${ }^{26} \mathrm{~A}$ transition to electric from internal combustion engines is expected to yield a lifecycle GHG emission reduction of 10-24 percent prior to AV adoption. ${ }^{27}$ In a lifecycle analysis of a shared AV taxi fleet, Gawron et al. estimated that the bulk of GHG reductions will come from electrification of the fleet-a 60 percent GHG emissions reduction from electrification, and up to 87 percent when power source, ridesharing, vehicle life, and computing power are included. ${ }^{28}$

The fuel economy of AVs, while expected to be better than human drivers, has substantial uncertainty, which means the associated GHG reductions are also uncertain. ${ }^{29}$ The programmed driving behavior of the AVs (aggressive versus conservative) could also predict the GHG reductions that we would expect. A more aggressively driving AV (one that drives closer to the vehicle in front of it) is expected to reduce GHG by 26 percent on highways, while more conservatively programmed AVs could actually increase emissions by 35 percent. ${ }^{30}$ It should be noted that the penetration rate of $A V s$ into the overall fleet of vehicles on the roadway is partly dependent on how aggressive AVs will be able to drive, as human drivers are not predictable nor always connected $(\mathrm{CV})$ to other vehicles on the roadway. A penetration rate of 75 percent or greater is expected to be needed for some benefits of connected autonomous vehicle (CAV) on the roadway to materialize. ${ }^{31}$ Consequently, some argue that we will not see any substantive changes in GHG from AVs alone in the short or medium term. ${ }^{32}$

Another key factor contributing to the potential climate impact of $A V$ s is whether self-driving vehicles would help shift transportation choices from an owned asset to a shared "service used on 
demand." ${ }^{33}$ Some have argued that AVs can remove many of the current carsharing barriers, such as the need to travel to access available vehicles. ${ }^{34}$ On the other hand, it is possible that only a small percentage of households will consider reducing the number of vehicles they own due to their overlapping trip schedules, and VMT could increase in metropolitan areas due to the mobility of unoccupied privately-owned AVs. ${ }^{35}$ While uncertainty in these issues exist, many scholars believe that the proliferation of ride-hailing services in recent years is a sign that AVs and on-demand mobility can be successfully combined. ${ }^{36}$ VMT has the potential to decrease "up to $24 \%$ compared to the human-driven vehicle baseline when dynamic ride-sharing was included" in the AV future, though VMT could increase "by $8-71 \%$ with no ride-share." ${ }^{37}$ Using a full-scale deployment model —one in which all VMT is shared - it was estimated that GHG emissions could be reduced by $40-50$ percent, and reduce parking demand by 95 percent. $^{38}$

Today's luxury vehicles are already using technology to connect to other vehicles and infrastructure. It is expected that this technology will spread rapidly with the deployment of $5 \mathrm{G}$ wireless technology. A connected vehicle (CV) is able to communicate hazards and roadway conditions to other vehicles, amongst other things. It is widely assumed that all AVs will also be connected vehicles, thereby improving the safety advantage of AV driven vehicles. It is not assumed, however, that all AVs will be shared vehicles-though given the cost these vehicles will have, many are estimating that more people will opt not to own their own AV.

Vehicle electrification - and by extension, the energy makeup of electricity supply — are other key factors affecting the GHG emissions of AVs. Many scholars have argued that ensuring significant GHG emissions reduction from the adoption of AVs and on-demand mobility will require that these vehicles not only be shared but also electric, ${ }^{39}$ or at least much more fuel efficient. ${ }^{40}$ Pavlenko found that the payback period for the purchase and use of electric vehicles is faster, two to three times faster, in fact, for ride-hailing drivers than typical private EV owners. Thus, this group of drivers could be further incentivized to purchase and use $\mathrm{EVs} .{ }^{41}$ One of the biggest barriers to EV adoption broadly, and specifically to ride-hailing drivers, is an insufficiently robust charging network for EVs. Bauer et al. have demonstrated that small investments could make EVs more cost effective than internal combustion engines for ride-hailing. ${ }^{42}$ Others are suggesting that once transportation is electrified, our next step in reducing transportation emissions should focus on decarbonization of the electricity supply. ${ }^{43}$ Consequently, we cannot simply think about AVs and their electrification in isolation, but rather as part of a larger network, regardless of how much VMT increases or decreases. ${ }^{44}$

Additionally, Shared Autonomous Vehicle (SAVs) that are also electric can further reduce GHG emissions through several advanced technologies. For example, Jones and Leib's energy system optimization model shows that SAVs can reduce GHG emissions through advanced technologies that help them drive more efficiently and avoid traffic, and also charge in alignment with renewable power output. ${ }^{45}$ Also, Taiebat et al.'s comprehensive review suggests that CAVs can yield higher energy efficiency through a variety of technology-enabled features, such as optimizing driving cycle, platooning, minimizing idling time, reducing cold starts, reducing speed fluctuations, self- 
parking, and eco-routing. ${ }^{46}$ As the share of vehicles on the road that are CAVs increases, we can expect greater reductions in GHG emissions because of improved end-to-end dynamic routing of the vehicles. ${ }^{47}$ In a CAV energy savings study by $\mathrm{Tu}$ et al., the authors did not find statistical differences between electric CAV and human-driven electric connected vehicle-though both had significantly better energy use than internal combustion engines. Furthermore, information systems and technologies that facilitate efficient "multi-hop" ridesharing can increase ride availability while simultaneously reducing congestion and emissions. ${ }^{48}$ A study of Lisbon, Portugal shows that SAVs could result in "97\% fewer vehicles, $95 \%$ less parking space, $37 \%$ fewer vehicle $\mathrm{km}$, and much lower operating costs." ${ }^{49}$

Since AVs are designed to eventually offer safer and more convenient mobility, ${ }^{50}$ it is very likely that a wide adoption of self-driving technologies will result in increased VMT by allowing nondrivers, seniors, and people with medical conditions to travel by car while reducing the time cost of travel. ${ }^{51}$ Kopelias et al. found that the improved safety from AV driven vehicles may allow for removing some physical safety features from vehicles that add substantial weight to vehicles. ${ }^{52}$ These changes have the potential to improve efficiency, and lower GHG emissions. Additionally, unoccupied privately-owned AVs will likely induce more VMT. ${ }^{53}$ Lastly, VMT might increase, if the convenience and accessibility offered by AVs discourage people from taking public transit. ${ }^{54}$ As a result, GHG emissions might increase despite energy efficiency benefits of AVs.

- The potential benefits of AVs and on-demand mobility will not be realized without proactive and progressive planning.

An analysis of the literature suggests that the relationship between $A V s$ and shared mobility and change of mobility preferences is simultaneous and self-reinforcing. Change in mobility preferences that involves placing a higher value for shared mobility (as opposed to individual mobility) can boost use of SAVs and on-demand mobility, and higher levels of adoption of such technologies can result in the overall desirability of shared mobility options. The literature offers some evidence that the desirable outcomes of AVs and shared and technology-enabled on-demand mobility will not be earned without change in mobility preferences. For example, through an analysis of low-carbon mobility patterns and an extensive literature review, Thomopoulos and Givoni concluded that the environmental and mobility benefits of AVs will only be realized if technological advancements are coupled with change of mobility preferences, where individuals prefer shared and public over individual and private. ${ }^{55}$ Yet, some argue that increased adoption of AVs, shared and on-demand mobility options will also contribute to such a shift in mobility preferences. As an example, Lane's (2005) first-year evaluation of "PhillyCarShare" initiative offers evidence of reduced vehicle ownership and change in mobility preferences as a result of the program. ${ }^{56}$ It should also be noted that public transportation can be competitive with shared mobility in its current form (e.g., UberPool) based on time-to-destination if passengers do not have to transfer or walk long distances to stops. This is an encouraging finding for splitting trips across modes to make the entire experience seamless. ${ }^{57}$ Splitting trips has been estimated in one 
instance of being able to reduce vehicle hours of traffic by 22 percent, thus reducing GHG emissions.

While AVs may free up time for leisure, Pudāne et al. found that this may create pressures or a sense of obligation to get more done during time that was once allocated for transportation. ${ }^{58}$ The corporate ownership of fleets, however, may hijack riders' time, eroding benefits gained by not navigating, by "harvesting [riders] attention through digital content, and repurposing it for financial gain"-thus riders will be watching advertising and be distracted from leveraging the newly gained time. This corporate ownership has the potential to reduce or eliminate the direct cost for riders because they are being subject to advertisement while riding, which could induce VMT, increase congestion, and result in increases in GHG emissions. This could be further exacerbated if the revenue model for corporate ownership is driven by ad revenue, which could result in AV driving patterns being maximized to increase the riders "exposure time to tailored content" rather than routing for the shortest trip. ${ }^{59}$

Overall, the literature offers reasons to believe that a positive social change favoring shared mobility is happening - regardless of whether or not it can be attributed to greater availability and popularity of technology-enabled shared mobility options. Cohen and Shaheen argue that the current economic, environmental, and social trends have contributed to the rapid growth of "shared economy," a term that would not make much sense to most until just a few years ago; yet, "shared economy" is now modifying how people travel. ${ }^{60}$ Shaheen, Mallery, and Kingsley claim that the current "collaborative consumption" patterns contribute to the development of new patterns of shared mobility, such as personal vehicle sharing (or peer-to-peer sharing) that appears to be amenable to lower density areas, where traditional carsharing is unlikely to flourish. ${ }^{61}$ Indeed, an economic model that values access and sharing as opposed to ownership provides impetus for optimism that AV and on-demand mobility technologies can also be utilized to provide equitable access to mobility without increasing VMT. And unlike taxi services, ride-hailing has been shown to provide access to transportation across all socio-economic groups. Brown found that in transitpoor neighborhoods, where the only options may be private vehicles, providers such as Lyft were providing service but taxis were not. ${ }^{62}$

Nevertheless, there is compelling evidence in the literature that without careful planning, all the optimism about the environmental and social benefits of AVs and on-demand mobility can vanish quickly. Numerous articles stress the importance of crafting policy measures and developing plans and strategies to ensure that AV and on-demand mobility technologies are effectively utilized to maximize the potential benefits and minimize the risk of counterproductive mobility, environmental, or societal outcomes. A policy brief published by the Institute of Transportation Studies at UC Davis identifies several "science-based policies" to ensure that AVs would be shared, energy efficient, safe and equitable and would not replace or discourage transit use or exacerbate congestion. ${ }^{63}$ 
To ensure that our "driverless future" serves the public interest without harming the environment, action should likely be taken at various levels ranging from companies that design and manufacture $A V s$ to the federal government. The literature offers examples of various types of actions that can be taken at different levels. For example, Hand argues that SAVs create an opportunity to "rethink" the way our cities have been designed through various strategies, such as eliminating parking lots, optimizing the accessibility of our communities, and building better quality streets that are designed to move people not vehicles. ${ }^{64}$ Friedman as well as Nyczepir share examples of state governments and municipalities respectively that are embracing the possible benefits of AVs by working with automobile manufacturers, tech companies, and residents. ${ }^{65}$

- To enhance mobility without increased VMT, AVs and on-demand shared mobility should augment and complement public transportation rather than replace it altogether.

One major subject explored by the literature is how AVs and on-demand mobility will impact mobility patterns and specifically the use and efficiency of public transportation. Interestingly, scholars do not yet agree on whether AVs and on-demand mobility options pose an "existential threat, ${ }^{\prime 66}$ disturb the operations, ${ }^{67}$ or are "key" to the future success of public transportation. ${ }^{68}$ Major reasons offered for why these technologies can potentially make public transportation (and especially commuter rail) "obsolete" ${ }^{69}$ or otherwise disrupted include the falling $\operatorname{cost}^{70}$ (especially due to effective ridesharing or ride-matching capabilities) and/or the comfort and convenience of these technologies. ${ }^{71}$ Nevertheless, most scholars would argue that despite potential challenges, $A V s$ and on-demand mobility options can offer opportunities to enhance mobility (without necessarily increasing VMT) especially when combined effectively with public transportation.

To enhance mobility, AVs and on-demand shared mobility should augment and complement transit rather than replace it altogether. Yet, "smart policies" and "the right price signals" are likely required to ensure success. ${ }^{72}$ Evidence suggests that a small but considerable percentage of trips offered by ride-hailing end at transit stations, ${ }^{73}$ and a significant percentage of ride-hailing trips occur between 10:00 PM and 4:00 AM, when transit services are likely to be unavailable. ${ }^{74}$ One strategy is to develop an effective collaboration between transit agencies or other public entities and the ride-hailing companies to ensure that these on-demand mobility services fill the gaps in the public transportation system and that the benefits are shared equitably. ${ }^{75}$ For example, ridehailing discount programs for the low-income or otherwise transit-dependent individuals can help connect them to transit effectively and conveniently. ${ }^{76}$ In addition to strategies that encourage ridesharing or the use of services that connect individuals to transit stations, pricing mechanisms can be used to alleviate traffic congestion that is exacerbated by ride-hailing in downtowns or otherwise dense urban areas with sufficient public transportation services. ${ }^{77}$

Additionally, shared active transportation modes (such as bikes and scooters) may also offer opportunities to augment public transportation while reducing GHG emissions. Sudmant et al. found GHG "emissions equivalent to removing approximately 9,000 vehicles off Shanghai streets are estimated to have been saved" through that city's bikeshare program. ${ }^{78}$ Nevertheless, shared 
active transportation modes are not considered viable first- and last-mile options for all transit riders. Therefore, a combination of first- and last-mile alternatives should be offered to ensure that the mobility needs of all populations are met.

- The equitable distribution of $A V s$ and on-demand mobility is crucial as a standalone goal but does not guarantee reduced GHG emissions.

The literature offers various scenarios and predictions about the first and/or major beneficiaries of AV and dynamic ridesharing technologies. A 2017 report published by the Victoria Transport Policy Institute indicates that "affluent non-drivers" would likely be the first group gaining "independent mobility" due to AVs. ${ }^{79}$ Others argue that young individuals are more likely to use $\mathrm{AVs}^{80}$ and SAVs. ${ }^{81}$ Additionally, several other factors will likely impact individuals' willingness or access to utilize AVs and dynamic ridesharing technologies, such as living in an urban area, current driving habits and travel patterns, and even home ownership. For example, the results of a random survey conducted for the National Renewable Energy Laboratory (NREL) suggests that younger individuals living in urban areas that rent their home and typically drive little are the most open to adopting AV technology. ${ }^{82}$ The results of another survey research indicate that younger populations and individuals whose travel patterns are typically multimodal are more likely to use SAVs; yet, several service attributes, such as travel cost, travel and waiting time, might be key determinants of the use and acceptance of both SAVs and dynamic ridesharing technologies. ${ }^{83}$

Wide and equitable distribution of $\mathrm{AVs}$ and on-demand mobility services can improve mobility through several mechanisms. For example, the Center for American Progress, ${ }^{84}$ as well as others, argue that ride-hailing can improve access to jobs, services, and amenities for disadvantaged populations by filling the geographic gap in public transportation services. ${ }^{85}$ In a number of communities in California where bus service was canceled due to low ridership, officials are providing discounts for people to use ride-hailing services. ${ }^{86}$ Additionally, several scholars observe that AVs and on-demand mobility services can improve independence and quality of life for people with disabilities and the elderly. ${ }^{87}$

Nevertheless, the equitable distribution of $\mathrm{AVs}$ and on-demand mobility services does not guarantee stable or reduced VMT or reductions in GHG emissions. In fact, Harper et al. find potentially substantial increases in VMT in a driverless future due to an increase in the mobility of seniors, non-drivers, and individuals with medical conditions. ${ }^{88}$ A 2019 report published by the Greenlining Institute argues that without "proactive regulations" simultaneously supporting both sustainability and equity, $A V_{s}$ would likely exacerbate traffic congestion, make public transportation less viable, and increase emissions. ${ }^{89}$ 


\section{The CAP and General Plan Analysis}

This chapter includes three major sections. The first section offers a detailed explanation of the methods followed to analyze CAPs and general plans from 23 Californian cities. The second and third sections describe findings from the analysis of CAPs and general plans, respectively.

\subsection{Methods}

\section{Case Study Selection}

The research team analyzed 23 Californian cities that are in more advanced stages of climate action planning. We chose these cities for special focus because, as the early actors in climate planning, they are the ones most likely to have thought through and experienced the challenges of reducing transportation emissions significantly. Thus, these cities are likely to have searched for new and innovative ways of successfully tackling GHGs from transportation.

These case studies were identified using a publicly available dataset produced by ICLEI-Local Governments for Sustainability, a global network of local governments dedicated to sustainability and climate action. ICLEI offers a systematic framework for climate planning that involves five major milestones, ranging from preparing a GHG emissions inventory to plan implementation, monitoring, and evaluation. ${ }^{90}$ From this dataset, we selected the 23 municipalities that in 2009 had reached at least the third milestone, developing a CAP. Our analysis of plans focused primarily on the latest versions of CAPs. If the city only updated parts of the CAP or referred to a previous version of the CAP, we reviewed both plans carefully. Table 2 shows the list of selected cities that have adopted a CAP since 2009 or earlier. 
Table 2. List of Municipalities

\begin{tabular}{|c|c|c|c|}
\hline City & Population & Region of CA & County \\
\hline American Canyon & 20,359 & Northern & Napa \\
\hline Arcata & 18,257 & Northern & Humboldt \\
\hline Berkeley & 121,643 & Northern & Alameda \\
\hline Emeryville & 12,104 & Northern & Alameda \\
\hline Fremont & 237,807 & Northern & Alameda \\
\hline Hayward & 159,620 & Northern & Alameda \\
\hline Los Angeles & $3,990,456$ & Southern & Los Angeles \\
\hline Menlo Park & 34,549 & Northern & San Mateo \\
\hline Napa & 79,263 & Northern & Napa \\
\hline Novato & 55,655 & Northern & Marin \\
\hline Oakland & 429,082 & Northern & Alameda \\
\hline Palo Alto & 66,666 & Northern & Santa Clara \\
\hline Rohnert Park & 43,753 & Northern & Sonoma \\
\hline Saint Helena & 6,152 & Northern & Napa \\
\hline San Diego & $1,425,976$ & Southern & San Diego \\
\hline San Francisco & 883,305 & Northern & San Francisco \\
\hline San José & $1,030,119$ & Northern & Santa Clara \\
\hline San Rafael & 58,704 & Northern & Marin \\
\hline Santa Cruz & 64,725 & Northern & Santa Cruz \\
\hline Santa Monica & 91,411 & Southern & Los Angeles \\
\hline Santa Rosa & 177,586 & Northern & Sonoma \\
\hline Windsor & 27,849 & Northern & Sonoma \\
\hline Yountville & 2,982 & Northern & Napa \\
\hline
\end{tabular}

Source: U.S. Census Bureau 


\section{Climate Action Plans (CAPs) and General Plans}

We chose to analyze both the CAP and general plan for each city, as these plans are often interrelated. CAPs are, as described above, strategic documents developed specifically to mitigate GHG emissions and build resilient communities. CAPs may provide detailed policy measures and implementation mechanisms to reduce GHGs from different sources, including transportation, or may simply offer visionary guidelines for future development of relevant policies and programs. On the other hand, general plans typically offer a broad set of guidelines in the form of future development goals as well as strategies to achieve those goals. Many cities have chosen to link their CAPs and general plans to shape their future in the face of climate change and build resilient communities.

Since CAPs and general plans typically work together to guide a city's vision and future development goals, it is important to look at both documents to fully understand whether a city is explicitly and comprehensively planning for AVs and on-demand mobility as tools to reduce GHG emissions. For instance, a city's general plan might refer to strategies offered in the CAP to further justify an action, or vice versa.

\section{The Plan Analysis Process}

To analyze the CAPs and their updates, four phases of analysis were employed. In Phase I, a framework was developed to capture specific information about strategies to reduce transportation emissions along with general information such as GHG emissions targets and baseline emissions levels. To create this framework, the research team drew upon a review of the climate planning literature and a sample of municipal CAPs. In Phase II, the research team pulled content from planning documents and coded them using the framework developed in Phase I. Subsequently, in Phase III, the research team coded content pulled in the second phase to identify TDM strategies as well as transportation infrastructure measures that were relevant to shared and/or on-demand mobility, ride-hailing, and AVs. Lastly, in Phase IV, findings from the content analysis of plans were compared with findings from the literature in order to identify untapped opportunities and possible risks of $\mathrm{AVs}$ and on-demand mobility.

\section{Phase 1}

For analysis of both CAPs and general plans, the research team created an analysis framework including the following categories of municipal actions:

- Strategies related to the physical transportation infrastructure, such as support for electric and autonomous vehicles, car-sharing, anti-car-idling ordinances, etc. 
- Land-use policies, such as transit oriented development, infill development, urban growth boundaries, open space and farmland preservation, parking reform, urban forests, port policies, etc.

- Transportation demand management (TDM) and related programs designed to encourage less single-occupancy vehicle driving

- Crosscutting issues and regional collaboration, such as implementing regional rail service that expands infrastructure for active and public transit

\section{- "Other," a category to capture innovative but uncommon strategies}

After establishing the content of this analysis framework, the research team created a matrix with each of the four primary categories (i.e., strategies related to physical transportation infrastructure, land-use policies, TDM, crosscutting issues) and the "other category." Sub-categories (e.g., "travel demand management for employers," "education and outreach," and "incentives to lessen driving") were added to the matrix under the appropriate primary category heading, to facilitate the coding processes in Phases II and III.

\section{Phase 2}

Utilizing the coding framework established in Phase I, two graduate research assistants worked collaboratively to review planning documents and identify text relevant to the four categories identified in our initial phase. After finding related text, the research assistants coded the text by copying the text verbatim into our matrix under the appropriate category and sub-category.

\section{Phase 3}

After the text for each plan had been pulled and categorized using our analysis framework matrix, the research team employed additional rounds of coding to mark 12 relevant categories of ondemand mobility and autonomous vehicles. The next step was to create two tables to synthesize and present the findings from the analysis of CAPs and general plans. In these tables, the research team put a checkmark next to a category only if the plan explicitly included a policy option, strategy or program that involved the category. For example, if the CAP included a general policy measure to encourage the use of shared mobility options, such as micro transit, but did not explicitly employ a measure relevant to micro transit, a checkmark was placed next to the broader category only. Similarly, if the CAP only recommended a specific pilot program to test the viability of micro transit, the research team did not count that as a shared mobility strategy in the analysis table. Also, if the CAP merely mentioned or included any of the relevant categories (e.g., by including a figure illustrating sustainable shared mobility options), but did not recommend an action item, such as a policy measure, action strategy or programmatic intervention, the research team did not count that as a relevant measure. 


\section{Phase 4}

Finally, the coded plans from all cities were analyzed again comprehensively to identify general themes in plan content, such as types of strategies CAPs or general plans recommended to utilize opportunities offered by on-demand and shared mobility or AVs. Findings from content analysis of plans were then compared with major findings from the literature review to identify untapped opportunities and possible risks from the deployment of AVs and expansion of on-demand mobility.

\subsection{Findings from the CAP Analysis}

Findings from the CAP analysis suggest that most cities are lagging behind to integrate $A V s$ and on-demand mobility as tools to achieve climate and equity objectives. As shown in Table 3, about one-third contained no policy options related to on-demand mobility and AVs, and the others typically included only a handful of relevant policies. More specifically, out of the 23 CAPs analyzed, seven did not include any policy options related to on-demand mobility and AVs. Among the 16 CAPs that included relevant policy measures, nine had two or three measures, six had four or five measures, and only one plan included seven measures.

Unsurprisingly, the more recent CAPs were more likely to include policy measures related to ondemand mobility and AVs. Among the seven CAPs that did not address on-demand mobility and AVs, six were adopted in or before 2012, and one was developed in 2015. In contrast, the CAPs that included five or more relevant policy measures were all adopted in or after 2016. San Rafael's plan that included a record of seven relevant policy measures was adopted in 2019. This finding stresses the importance of regularly updating CAPs.

Although CAPs included different mixes of policy options, some categories were more commonly mentioned than others. The most common type of relevant policy measures dealt with carpooling and ride-sharing; nine and ten CAPs recommended a relevant measure, respectively. The next most common options were car-sharing and vanpooling (each mentioned in seven plans) and shared mobility (mentioned in six plans). 
Table 3. On-Demand Mobility and AV Measures in CAPs

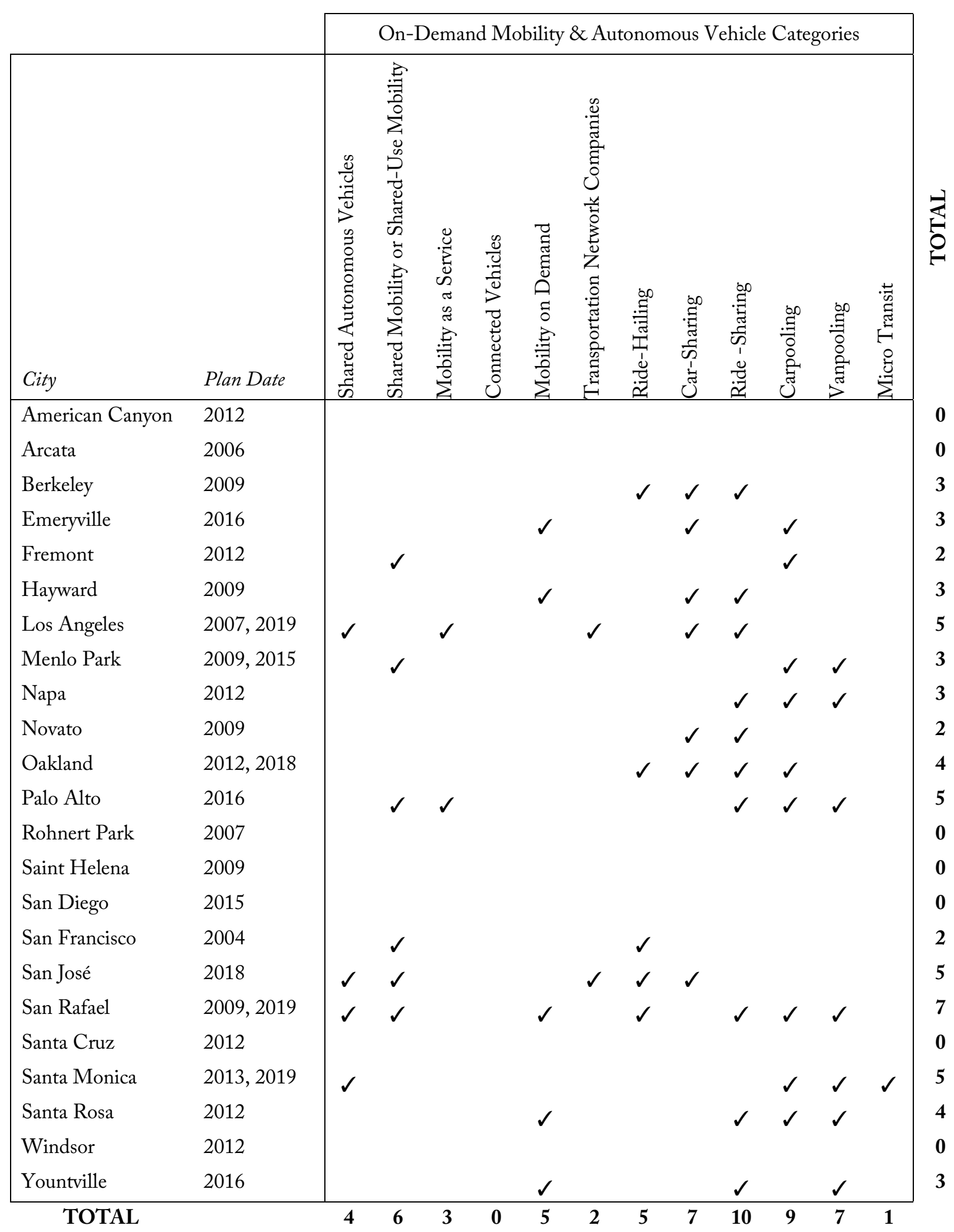


CAPs recommended a variety of types of actions to encourage ride-sharing (including carpooling and vanpooling) and car-sharing. For example, many CAPs incorporated specific measures to incentivize and/or educate city employees to benefit from these mobility options. In addition, or as alternatives to programs designed for city staff, several CAPs recommended working with employers (especially major employers) as well as transportation funding agencies to incentivize (or remove the disincentives of) these mobility options. Examples include: the City of Hayward's CAP, which recommends helping businesses (particularly large employers such as colleges and the Hayward Unified School District) to develop and implement car-sharing programs; the City of Oakland's CAP, which recommends encouraging and assisting employers as well as transportation funding agencies to offer support for a variety of mobility options that reduce the need for driving, including but not limited to ride-sharing, car-sharing, carpooling and vanpooling; the City of Santa Rosa's CAP, which recommends working specifically with large employers to develop ridesharing programs, including carpool and vanpool alternatives; and Freemont's CAP, which recommends requiring employers to offer preferential parking for carpools. Additionally, CAPs included measures that were meant to more broadly benefit the entire community and/or disadvantaged groups. Examples include: Los Angeles's integration of car-sharing services into the first- and last-mile infrastructure improvement program around transit stations; and Berkeley's action item of providing car share subsidies for low income residents.

The broader category of shared-mobility, which includes any transportation service that is shared among users, ranging from public transportation and shuttle service to ride-sharing and scootersharing, was specifically mentioned in six CAPs. Examples of relevant shared-mobility programs and policies include: Freemont's "commuter shuttle service" program which connects business districts to major transit stations; Menlo Park's shuttle program that offers "around-town" transportation; San Francisco's "Hall of Justice Employee Shuttle" that provides close to 20,000 passenger-trips a year to and from the Civic Center Station; the City of Palo Alto's policy measure of increasing shared transportation ridership rates through a variety of programs; and the City of San José's partnerships with relevant organizations to collect and analyze data related to sharedmobility (to gain insights for better incorporation of shared-mobility options into the City's CAP).

Mobility on demand and ride-hailing measures were each mentioned in five CAPs. The main goal of mobility on-demand is to provide people with efficient transportation choices that fit their unique needs and circumstances. Current technologies empower individuals to benefit from ondemand information, real-time data, and even predictive analysis to better meet their transportation needs. As such, mobility on-demand and ride-hailing have been viewed by several CAPs as an effective way to alleviate the limitations of shared-mobility and alternative transportation modes. For example, "guaranteed" or "emergency" ride home programs (that guarantee participants using alternative transportation modes a ride home in case of unexpected emergencies) as well as "on-demand shuttles" or "micro-transit" have been recommended by several CAPs. Nevertheless, among the CAPs that stress the importance of mobility on demand, only a few propose action items that specifically focus on the use of technology-enabled services. 
Examples include: Berkeley's marketing and outreach efforts to promote the development of realtime or dynamic ride-matching; Palo Alto's strategy of facilitating dynamic commute ride sharing as well as promoting the use of various smartphone applications; and Santa Monica's promotion of "micro-transit," which the City defines as technology-enabled private shuttle services with dynamic routes (rather than fixed routes) and stop locations (as opposed to a door-to-door service). A few cities have also proposed the innovative option of combining facilitation of ride-hailing with zero emission vehicles to enhance the GHGs reduction potential of their relevant policy measures. For example, the City of San Rafael's CAP calls for encouraging or requiring ride-hailing (as well as delivery service companies) to utilize zero emission vehicles.

Only four recently updated municipal CAPs specifically mentioned shared autonomous vehicles. Most interestingly, all of these CAPs combined measures of preparation for autonomous vehicles with GHG emission reduction and/or transportation equity and accessibility goals. For example, the City of Los Angeles' 2019 CAP entitled “L.A.'s Green New Deal," proposes initiatives to ensure that AVs are effectively utilized for sharing services and are electric. Meanwhile, L.A.'s 2019 CAP stresses the importance of analyzing transportation data and creating design guidelines for AV infrastructure to ensure equitable distribution of app-enabled mobility services across the City. Although the City of Santa Monica's 2019 CAP views AVs as an electrified and shared mobility option, it also acknowledges the need to plan for future use of $A V$ s to minimize the possibility of adverse impacts, such as increased VMT or congestion, or jeopardized road safety. Similarly, the City of San José's 2018 CAP calls for regulation to reduce GHG and VMT impacts of AVs by making driving alone more expensive and promoting mode shifts. San José also plans to partner with public and private organizations to ensure accessibility and affordability of AVs to low-income individuals. Lastly, San Rafael offers a different measure to reduce GHGs from AVs: limiting idling of AVs through public engagement campaigns.

Another alternative to combine GHGs reduction and transportation accessibility goals focuses on ride-hailing. For example, the City of San José is evaluating options, such as discounted group EV purchasing or permitting incentives, to encourage ride-hailing companies to use EVs. Meanwhile, the City of Los Angeles partnered with a ride-hailing provider to help connect residents to public transit.

Mobility as a Service (MaaS) is yet another relevant term discussed in municipal CAPs that is meant to offer a "consumer-centric" model of transportation through streamlining "journey planning." MaaS eliminates the need for separately planning, booking, and paying for various transportation services (including shared and micro-mobility offerings) used to get to a final destination. As such, MaaS can reduce barriers for using alternative modes of transportation and shared mobility, thus reducing VMT and GHGs. Examples of measures or programs incorporating MaaS into municipal CAPs include: City of Palo Alto's measure to promote and facilitate apps that offer seamless mobility payment and booking options; and the City of Los Angeles's partnership with a ride-hailing company to connect nearby residents to public transit 
either free of charge (for those enrolled in the low-income transit subsidy program) or for a small fee using a Transit Access Pass (TAP) card.

\subsection{Findings from the General Plan Analysis}

Compared to CAPs, municipal general plans were far less likely to include explicit interventions to ensure that $A V s$ and on-demand mobility help communities reduce GHG emissions. Yet, several municipal general plans have adopted policy measures related to shared and on-demand mobility and AVs (see Table 4). Out of 23 general plans analyzed, five plans included four or five, and six plans included two or three relevant measures. Three other plans included at least one relevant measure, and the remaining nine plans did not specifically mention any of the relevant policy categories in their general plans.

An analysis of general plans shows that municipalities have focused on various categories of shared and/or on-demand mobility and AVs through four different type of policy mechanisms: (1) transportation system management or travel demand management for employers; (2) incentives to lessen driving in general; (3) education and outreach programs; and (4) development of emerging transportation technologies (as related to transportation infrastructure). 
Table 4. On-Demand Mobility and AV Measures in General Plans

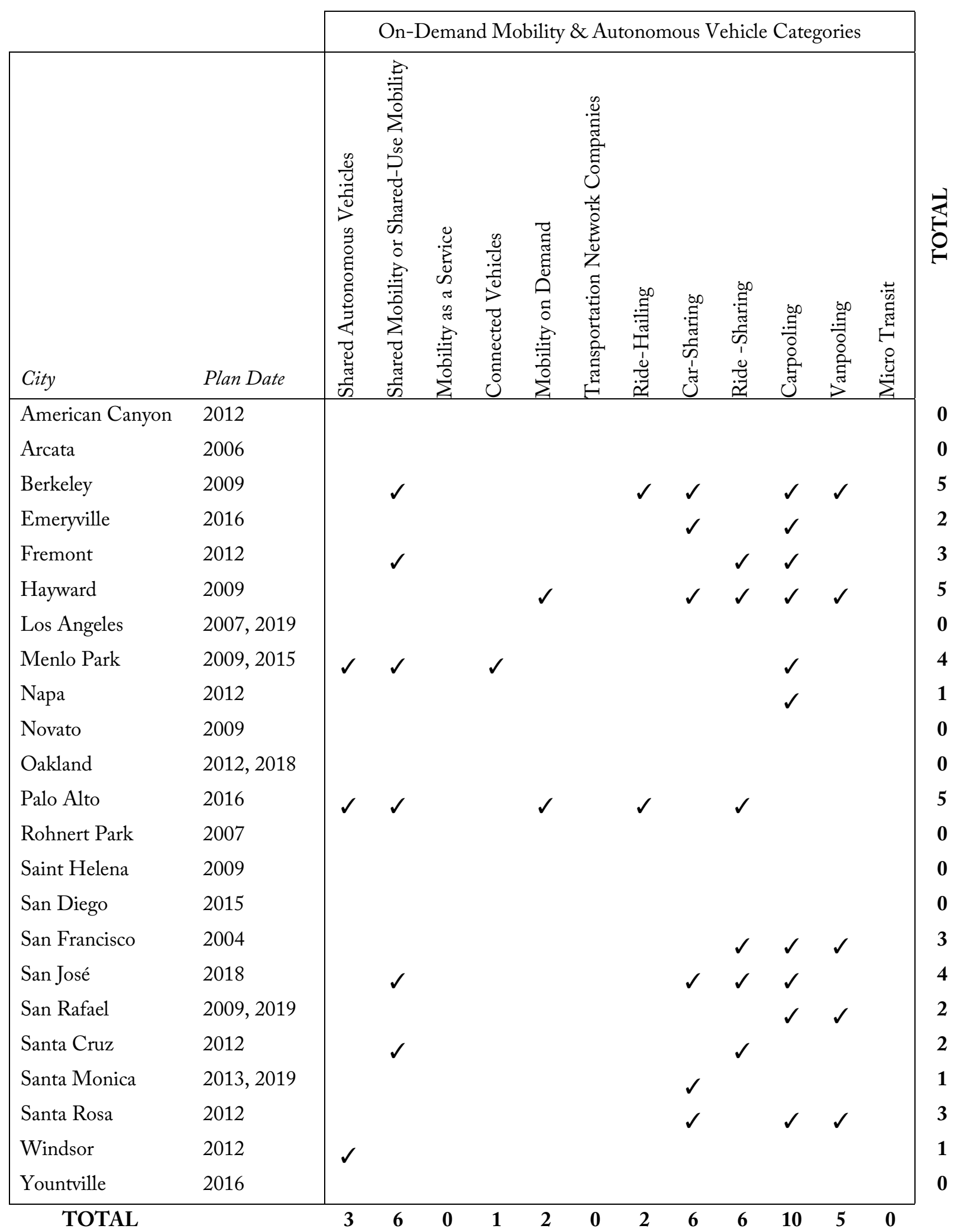


Like in CAPs, the most common relevant policy category included in municipal general plans was carpooling, with ten municipalities specifically adopting at least one relevant policy. These municipalities have adopted TDM policy options to encourage commuters to carpool, such as the provision of carpool parking; community outreach initiatives to encourage carpooling; TDM programs for major employers and school districts; and guaranteed ride home programs. For example, the City of Berkeley's "Trip Reduction" policy specifically mentions "carpooling and provision of carpool parking and other necessary facilities" as a mechanism to reduce automobile traffic and congestion. Within the same policy measure, Berkeley proposed programs to facilitate carpooling through neighborhood-level initiatives. Additionally, Berkeley's general plan includes a policy measure to encourage private employers reduce the demand for automobile travel through carpool incentives. The general plans of Menlo Park and San Rafael aimed at expanding the effectiveness of their TDM programs by proposing to specifically encourage carpooling for school trips in addition to work trips. Napa, on the other hand, adopted a policy to encourage commercial developers (with projects that will likely employ at least 50 individuals) to provide preferential parking for carpool. Lastly, Hayward's general plan stressed the importance of creating "Transportation Management Associations" and eliminating barriers to carpooling through various programs, such as "guaranteed ride home" programs. These diverse examples show how municipal plans have considered different strategies to encourage carpooling as a more desirable transportation option compared to driving alone.

Shared mobility, car-sharing and ride-sharing have each been mentioned specifically in six, and vanpooling in five municipal general pans. All of these categories have been considered an effective first- and last-mile solution by municipal general plans that can eliminate or alleviate barriers to the use of public transit. As such, a specific attention has been given to transit dependent or vulnerable populations, such as the disabled, seniors, and youth. For example, Berkeley's general plan includes a "Special Transit Program" that offers "senior vans" to improve mobility for the elderly. Additionally or alternatively to TDM strategies for major employers and beyond, a number of cities have also developed district-specific programs that facilitate shared mobility in high-traffic or high-demand areas. Examples include Santa Cruz's shuttle services for the downtown area and other major employment centers; Menlo Park's shuttle service connecting employment centers and the Downtown Menlo Park Caltrain station; and Berkeley's "no-fare shopper shuttles" that connect shopping districts in the entire City.

Similarly, ride-hailing and mobility on demand have both been mentioned in two municipal general plans as strategies to remove barriers to the use of public and alternative transportation modes. For example, Palo Alto's general plan emphasizes the need for services that "complement and enhance" alternative mobility options available to their residents and "expand transit access," including but not limited to ride-hailing services and on-demand local shuttles. As part of the City's "Employer-based Strategies," Hayward's general plan mentions mobility on demand strategies, such as guaranteed ride home programs to strengthen chances of success for employerbased TDM strategies. 
Only three out of 23 municipal general plans have included provisions for relevant emerging transportation technologies, namely, CAV. Among these three cities, only the general plans of Palo Alto and Menlo Park briefly focus on possible opportunities for GHG emissions reduction from these technologies. Both of these general plans stress the importance of supporting or funding emerging technological advancements, such as, but not limited to, connected and autonomous vehicles, sharing technology, and EV technology to reduce air pollution and GHG emissions and to enhance access to mobility for all. Winsor's general plan, on the other hand, focuses primarily on the potential impacts of driverless vehicles on the streets of the Town, such as impacts on roadway design, signage, and speed limits. No general plan included measures related to ridehailing, specifically how to encourage ride-hailing companies to adopt technologies and practices that can help reduce GHG emission.

One could argue that the reason AVs received limited attention in general plans (as well as CAPs) in California is the uncertainties involved in market penetration of these technologies. Although $\mathrm{AVs}$ are one of the most discussed technologies in transportation today, there still are many technical and non-technical challenges involved in effective and widespread deployment of AVs. These challenges and uncertainties may caution planners and policymakers about immature decisions and unrealistic expectations which can discourage action altogether. Nevertheless, inaction may also involve significant risks and lost opportunities to maximize the environmental and equity benefits of these technologies. Hence, the next chapter focuses on ways cities can harness the GHG emissions mitigation and mobility equity benefits of $A V s$ and on-demand mobility. 


\section{Conclusions and Discussion of Policy Implications}

This chapter concludes the report with a summary of key findings, discussion of the policy implications that flow from those findings, and an assessment of the study limitations paired with suggestions for future research.

\subsection{Summary of Major Findings}

Analysis of the literature, municipal climate action plans (CAPs) and general plans yielded important findings about: (1) the potential benefits as well as risks of AVs and on-demand mobility; (2) actions communities have taken to seize the benefits and minimize the potential downsides or risks associated with driverless vehicles and app-enabled on-demand mobility; and (3) untapped opportunities for reducing GHG emissions from transportation and contributing to equitable mobility through planning efforts. Most importantly, findings of this research suggest that:

(1) Policy and planning discussions should consider synergies between autonomous vehicles (AVs) and on-demand mobility as two closely related emerging mobility trends.

The literature focusing on vehicle automation technologies overlaps with that of on-demand mobility. This is mainly because of the synergies between AVs and on-demand mobility that may help amplify adoption as well as benefits of both while reducing the risk of negative environmental or social impacts. For example, AVs can boost carsharing by eliminating the need for someone to travel to a carsharing facility to access available vehicles, ${ }^{91}$ and improving safety, and convenience. If $A V s$ are shared and used as a mobility service (as opposed to privately-owned single-occupancy vehicles), concerns about increased traffic, VMT, and consequently GHG emissions are significantly reduced. Shared AVs (or SAVs) are also more likely to be accessible to a wider range of users making their widespread and equitable adoption possible. Due to the synergies between $A V s$ and on-demand mobility, any discussion of maximization of benefits or minimization of risks should consider both of these emerging trends.

(2) Several factors determine whether the deployment of AVs would help reduce GHG emissions from transportation, as well as the extent of these environmental benefits.

An analysis of the literature indicates that three major types of factors play a role in the potential GHG emissions impact of AVs: (1) factors related to the technology, functionality, and efficiency of AVs (e.g., vehicle electrification, fuel efficiency, size, connectedness, etc.); (2) factors related to the use and ownership of $A V s$ (e.g., shared vs. single occupant; publicly-owned vs. privately-owned vehicles); and (3) factors related to access, distribution, and convenience of use of AVs across 
geography and for various population groups (e.g., wide or limited distribution of AVs in urban and suburban areas). Due to uncertainties involved in how these factors will vary in the future, projections for GHG emissions impact of AVs involve a wide range of possible outcomes. The most optimistic projections can promise an 80 percent or even greater reduction in GHG emissions; whereas the most conservative estimates predict a significant increase in GHG emissions due to increased VMT and unmet energy efficiency goals.

\section{(3) AVs and on-demand mobility can potentially contribute to a more equitable transportation system.}

Findings from the literature suggest that AVs and on-demand mobility can contribute to building a more equitable transportation system both directly and indirectly. These technologies can directly improve independence and quality of life for individuals with disabilities and the elderly, enhance access to transit by offering a viable solution for the first- and last-mile problem, and help alleviate the geographic gap in public transportation services. In terms of indirect impacts, wide adoption of SAVs can reduce demand for parking and create an opportunity for in-fill development and affordable housing especially in urban areas that offer better access to jobs, amenities and services, including transportation options.

(4) Maximizing the environmental and social benefits of $A V s$ and on-demand mobility requires proactive and progressive planning; yet, most cities are lagging behind in this area.

A comparison of findings from the literature and analysis of municipal CAPs and general plans shows that the environmental and social benefits of AVs and on-demand mobility will not be realized without a comprehensive strategic vision about what an ideal transportation system should look like, and what steps should communities take to get there. Nevertheless, one clear finding was that few cities were comprehensively planning to integrate AVs and on-demand mobility as tools to achieve climate and equity objectives. Close to one-third of the cities did not include any policy options related to on-demand mobility and AVs in their CAPs. And among the two-thirds of CAPs that did include relevant policy measures, few had more than a handful. Unsurprisingly, the more recent CAPs were more likely to include policy measures related to shared and ondemand mobility and AVs. This reflects the importance of regularly updating CAPs to incorporate opportunities and challenges that new technologies present.

Promisingly, lessons learned from TDM strategies adopted by municipal plans-such as the need to combine various awareness, pricing and incentive-based strategies to influence mode choice and travel demand; or the importance of effective collaboration between transportation agencies, local governments, businesses, and nonprofit organizations - can still be relevant in a driverless future. Similarly, land-use policies adopted by local plans to encourage high-density, mixed-use, and infill development or planning efforts to build walkable and transit friendly communities are still valid tools to reduce VMT and GHG emissions. Nevertheless, AVs and on-demand mobility offer new 
opportunities and pose new challenges for communities that should not be ignored in planning efforts.

(5) Municipal CAPs and general plans in California have adopted several strategies and programs relevant to $A V$ s and on-demand mobility.

Since several common TDM strategies, such as programs or policies to encourage carpooling, are applicable to AVs and on-demand mobility, the majority of municipal CAPs analyzed included at least a few relevant measures. The more recently updated CAPs were more likely to include a larger number and more closely relevant measures to $A V s$ and on-demand mobility, such as initiatives to ensure that $A V_{s}$ are shared and electric, more accessible to low-income individuals, and more efficiently used by minimizing idling time. Other innovative measures adopted by recently updated CAPs involve measures to encourage TNCs to invest in electric vehicles; programs to promote "Mobility As A Service" or MaaS through apps that offer seamless mobility payment and booking options; and partnerships with ride-hailing companies to connect nearby residents to public transit either free of charge or for a small fee.

As expected, municipal general plans were far less likely to include explicit interventions to ensure that AVs and on-demand mobility help communities reduce GHG emissions. The few plans that did include provisions for relevant emerging transportation technologies of interest focused predominantly on bigger picture ideas, such as supporting research and development for AVs and other technological advances and planning for infrastructure investments and improvements.

(6) Several untapped opportunities exist to harness the GHG emissions reduction and social benefits potential of $A V$ s and on-demand mobility.

A comparison of findings from the literature review and analysis of municipal CAPs and general plans in California uncovers untapped opportunities to seize the GHG emissions reduction and social benefits of AVs and on-demand mobility. The following section details ways and mechanisms through which CAPs can help communities plan for environmentally responsible and socially equitable adoption of $\mathrm{AVs}$ and on-demand mobility.

\subsection{Discussion of Policy Recommendations}

The study findings outlined above suggest a number of specific ways that local governments can harness the GHG emissions mitigation and equity potential of on-demand mobility and autonomous vehicles:

\section{(1) Use CAPs as a tool to ensure equitable mobility in a driverless future.}

Since climate action planning and policy inventions are constantly engaging with the notion of just and equitable communities, ${ }^{92}$ existing or common measures utilized by CAPs can be strengthened 
to guide the equitable distribution and use of $A V$ s and technology-enabled on-demand mobility. The recently updated generation of CAPs more prominently acknowledge that effective climate action planning is rooted in social justice and equity. CAPs commonly stress the importance of protecting the most vulnerable among our communities, and prioritizing resources to address inherent inequities in our society, such as lack of access to safe, affordable, and convenient public or active transportation options. Since $A V_{s}$ and on-demand mobility options present both an opportunity to alleviate the equity gaps in our current transportation system and a risk of exacerbating such inequities, ${ }^{93}$ local governments should ensure that their CAPs employ specific measures to maximize the potential benefits and minimize the risks. For example, CAPs can include policy and programmatic interventions to encourage or incentivize the use of shared AVs and on-demand mobility options as an affordable and convenient first- and last-mile solution.

\section{(2) Provide comprehensive GHG emissions reduction roadmaps for $A V$ s and on-demand mobility to reinforce general plan mobility goals.}

As discussed in the findings section of this report, both municipal CAPs and general plans may include measures relevant to AVs and on-demand mobility. Nevertheless, CAPs are more likely to offer a clear and comprehensive guide for developing, coordinating, and implementing community programs to reduce GHG emissions and adapt to the adverse impacts of climate change. In other words, general plans are more suited to provide a broader vision; CAPs are more appropriate for providing detailed guidelines and innovative solutions specifically designed to combat climate change. As such, a GHG emissions reduction roadmap for AVs and on-demand mobility can be added to transportation demand management (TDM) strategies, as well as physical transportation infrastructure strategies, land-use policies, and regional coordination efforts highlighted in the CAPs. The CAP can then be linked to the general plan to reinforce its broader mobility goals.

\section{(3) Encourage travelers to make a long-run shift to shared use of AVs and on-demand mobility.}

There is a general consensus in the literature that the potential benefits of AVs and on-demand mobility, such as reduced VMT, GHG emissions and traffic, will only be realized if these technologies make shared mobility more economical, flexible, and convenient, and, by extension, more common or desirable. The widespread availability of app-enabled on-demand mobility options, dynamic geo-positioning technologies, and ease of electronic financial transactions, have cleared major hurdles of carpooling. Furthermore, AVs can help reduce or eliminate safety incidents, such as crashes and even assaults. Nevertheless, additional incentives might be required to shift the mobility preferences of individuals who always relied on private vehicles.

TDM strategies recommended by CAPs, such as preferential parking for carpools, employee subsidies for carpooling, shuttle programs for business and entertainment districts, and guaranteed ride home programs for commuters who carpool or otherwise use public or active modes of transportation can be a good start. Nevertheless, most of these strategies have been designed for 
static ridesharing, and do not necessarily reflect the opportunities and challenges offered by AVs and dynamic ridesharing technologies that better support impromptu trips. Thus, there is a need to redesign TDM strategies recommended by CAPs to encourage shared use of AVs and ondemand mobility and help shift mobility preferences of individuals towards shared mobility in the long-run.

(4) Use a combination of transportation and land-use policies to prevent increasing sprawl due to deployment of $A V s$.

Local CAPs typically recommend a variety of transportation and land-use strategies to combat sprawl, ranging from in-fill and transit-oriented development strategies to eliminating parking minimums. To ensure that the increased comfort and reduced value of travel time (due to reduced opportunity cost of driving) associated with AVs will not inadvertently result in sprawl, local CAPs should utilize both transportation and land-use progressive policy options. It is important to note that the combined effect of transportation and land-use policy options is often greater than the effect of one type of policy. This is because transportation and land-use policies work together in affecting travel behavior. For example, by eliminating parking minimums, CAPs can encourage shared use of AVs as well as discouraging the private ownership of AVs. If most or all AVs are shared and used as service on-demand, the need for parking space will further diminish resulting in an in-fill development opportunity. This synergic effect between transportation and land-use policies should not be disregarded.

\section{(5) Stress the importance of energy efficiency and renewable energy in a driverless future.}

The biggest motivation for the development and deployment of AVs is increased safety and convenience- a robot will replace the driver, and it will follow all traffic rules and cannot be distracted. Other potential advantages of AVs, such as reduced GHG emissions, are considered co-benefits. These co-benefits are not necessarily guaranteed by manufacturers. Manufacturers might actually be tempted to build larger vehicles that can serve other purposes, such as an office, a gym, or a movie theater. These larger vehicles can be even more energy consumptive than the current single-purpose vehicles. Local CAPs can help develop and adopt specific policies to ensure that AVs are energy efficient and/or electric. In addition to supporting electrification of transportation, local CAPs can also encourage or require use of renewable energy in electricity generation.

\section{(6) Identify opportunities to link AVs and on-demand mobility to transit.}

One major challenge associated with widespread deployment of AVs is the potential for declined transit ridership, decrease in public transportation funding, and eventually reduced options for the ones who do not have access to a car. However, declined transit ridership followed by reduced funding and transportation options is not the only possible scenario. The alternative scenario is that $\mathrm{AVs}$ and on-demand mobility options will be used to augment and complement public 
transportation. CAPs typically offer a variety of options to enhance the viability of public and active modes of transportation, ranging from local initiatives to regional coordination for rail service infrastructure. CAPs also include first- and last-mile solutions to boost transit ridership. A combination of these strategies can be specifically designed to utilize the opportunities offered by $\mathrm{AVs}$ and on-demand mobility options to connect individuals to transit stations easily or fill the mobility gaps in areas with limited or nonexistent transit options. For example, one simple but effective strategy is developing web-based streamlined trip planners that offer real-time departure predictions and eliminate the need for checking different transit maps or websites, planning for the trip to and from transit stations, and purchasing separate fare passes. Another strategy is offering discounted ride-hailing service to and from transit stations. In sum, making the transit experience better and easier involves planning for the entire trip, not just the transit portion of it.

\section{(7) Incorporate planning tools that respond to the uncertainty related to deployment of AVs and extensive use of on-demand mobility technologies.}

Since climate change poses many uncertainties, CAPs have long considered sophisticated and dynamic methods to deal with them. For example, scenario analysis is a major tool used by CAPs to project alternative possible outcomes based on scientific and economic factors as well as policy interventions. CAPs have also acknowledged that uncertainties can discourage action, and thus recommended techniques to help stay focused on the desirable goals or outcomes. For example, back casting-which is a planning technique that first defines a desirable future or goal and then works backwards to identify policy and programmatic interventions that connect the present conditions to the desired future outcome-is a commonly used technique by CAPs. These common methods of dealing with uncertainties through CAPs can be used to help local governments envision a desirable mobility outcome in a driverless future and ensure that deployment of AVs and more extensive use of on-demand mobility will help us reduce GHG emissions and VMT as well as improve mobility for all.

\subsection{Study Limitations and Recommendations for Future Research}

Because AVs and on-demand mobility rely on rapidly evolving technologies and business practices, it will be important to regularly update the findings presented in this report. The literature is expanding rapidly, for example. Also, local governments periodically update their CAPs, and new plans will most likely include more content related to AV and on-demand mobility.

The Covid-19 pandemic has changed travel behaviors significantly in 2020. What we do not yet know is if these changes to travel behavior will be long-lasting, if we will return to previous practices of transportation once a vaccine is developed, or if some third, unknown, new travel behavior will exist. There is some anecdotal evidence that some people will be less likely to want to use shared mobility in the future, whether that is public transportation or a shared on-demand trip. This could dramatically alter the trajectory of the future of transportation in ways that we do not yet understand. 
A relatively small number of plans were reviewed for this report. These were also chosen because the cities are leaders in climate action planning, not necessarily leaders in planning for new transportation technologies. It would be useful to review what other cities are doing, including cities in other states. One fruitful avenue will be to select cities that are aggressively courting new mobility companies. At the same time, it would also be valuable to review planning efforts from cities that are not at the cutting edge of either climate action planning or transportation technology adoption. This broader consideration of CAPs would provide insight on what planning efforts these more typical localities are (or are not) taking to take advantage of $A V s$ and shared-use mobility.

It is important to note that the disparities in the ways various cities or regions are (or are not) planning for $\mathrm{AVs}$ and on-demand mobility might also create equity concerns. This report briefly discussed mobility equity issues relevant to local CAPs. Nevertheless, equity concerns related to deployment of $\mathrm{AVs}$ and expansion (or lack thereof) of on-demand mobility go beyond the subject of this report. Future studies can focus on broader dimensions of equity related to AVs and ondemand mobility.

Lastly, climate action planning (or lack thereof) involves many equity considerations that go beyond the scope of this report but raise many interesting research questions. Evidence from our analysis suggests that the current generation of CAPs tend to combine climate action planning efforts with social equity goals. The most recent example is the City of Oakland's newly released CAP entitled "Oakland 2030 Equitable Climate Action Plan" which explicitly emphasizes the need to ensure that frontline communities (i.e., communities harmed by environmental injustice that are likely to be hard hit by the impacts of climate change) are protected. Future research can focus on how these new or updated CAPs are affecting social equity, while also reducing a community's contribution to climate change. 


\section{Abbreviations and Acronyms}

$\begin{array}{ll}\text { AV } & \text { Autonomous vehicle } \\ \text { CAP } & \text { Climate action plan } \\ \text { CV } & \text { Connected vehicle } \\ \text { GHG } & \text { Greenhouse gas } \\ \text { MaaS } & \text { Mobility as a service } \\ \text { SAV } & \text { Shared autonomous vehicles } \\ \text { TDM } & \text { Transportation demand management } \\ \text { TNC } & \text { Transportation network company } \\ \text { VMT } & \text { Vehicle miles traveled }\end{array}$




\section{Endnotes}

${ }^{1}$ Adriano Alessandrini et al., "Automated Vehicles and the Rethinking of Mobility and Cities," Transportation Research Procedia 5 (2015): 145-60; Lauren P. Alexander and Marta C. González, "Assessing the Impact of Real-Time Ridesharing on Urban Traffic Using Mobile Phone Data," Proc. UrbComp (2015): 1-9; Jeffery B. Greenblatt and Samveg Saxena, “Autonomous Taxis Could Greatly Reduce Greenhouse-Gas Emissions of US Light-Duty Vehicles," Nature Climate Change 5, no. 9 (2015): 860; Corey D. Harper et al., "Estimating Potential Increases in Travel with Autonomous Vehicles for the Non-Driving, Elderly and People with Travel-Restrictive Medical Conditions," Transportation Research Part C: Emerging Technologies 72 (2016): 1-9; Todd Litman, Autonomous Vehicle Implementation Predictions (Victoria Transport Policy Institute, 2017); Zia Wadud, Don MacKenzie, and Paul Leiby, "Help or Hindrance? The Travel, Energy and Carbon Impacts of Highly Automated Vehicles," Transportation Research Part A: Policy and Practice 86 (2016): 1-18; Wenwen Zhang et al., "Exploring the Impact of Shared Autonomous Vehicles on Urban Parking Demand: An Agent-Based Simulation Approach," Sustainable Cities and Society 19 (2015): 34-45; Pantelis Kopelias et al., "Connected \& Autonomous Vehicles-Environmental Impacts-A Review," Science of the Total Environment 712 (2020): 135237.

${ }^{2}$ S.M. Patella et al., "Carbon Footprint of Autonomous Vehicles at the Urban Mobility System Level: A Traffic Simulation-Based Approach,” Transportation Research Part D: Transport and Environment 74 (2019): 189-200.

${ }^{3}$ Litman, 2017; Wadud, MacKenzie, and Leiby, 2016.

${ }^{4}$ Patella et al., 2019.

${ }^{5}$ Patella et al., 2019

${ }^{6}$ Nelson D. Chan and Susan A. Shaheen, "Ridesharing in North America: Past, Present, and Future," Transport Reviews 32, no. 1 (2012): 93-112; Michael Liebman, "What Mobility as a Service (MaaS) Means for the Transportation Industry," GreenBiz, June 11, 2018, https:/www.greenbiz.com/article/what-mobility-service-maas-means-transportation-industry; Nikolas Thomopoulos and Moshe Givoni, "The Autonomous Car-A Blessing or a Curse for the Future of Low Carbon Mobility? An Exploration of Likely vs. Desirable Outcomes," European Journal of Futures Research 3, no. 1 (2015): 14.

${ }^{7}$ Austin Brown, Jeffrey Gonder, and Brittany Repac, "An Analysis of Possible Energy Impacts of Automated Vehicle," in Road Vehicle Automation, pp. 137-153 (Springer, 2014); William R. Morrow et al., "Key Factors Influencing Autonomous Vehicles' Energy and Environmental Outcome," in Road Vehicle Automation, pp. 127-135 (Springer, 2014); National Research Council, Transitions to Alternative Vehicles and Fuels (National Academies Press, 2013); Kpelias et al., 2020. 
${ }^{8}$ Yi Sui et al., "GPS Data in Urban Online Ride-Hailing: A Comparative Analysis on Fuel Consumption and Emissions," Journal of Cleaner Production 227 (2019): 495-505.

${ }^{9}$ Wadud, MacKenzie, and Leiby, 2016.

${ }^{10}$ Corina McKendry, "Cities and the Challenge of Multiscalar Climate Justice: Climate Governance and Social Equity in Chicago, Birmingham, and Vancouver," Local Environment 21, no. 11 (2016): 1354-1371.

${ }^{11}$ Cambridge Systematics, Moving Cooler: An Analysis of Transportation Strategies for Reducing Greenhouse Gas Emissions (Washington, DC: Urban Land Institute, 2009).

${ }^{12}$ Michael R. Boswell, Adrienne I. Greve, and Tammy L. Seale, Local Climate Action Planning (Island Press, 2012).

${ }^{13}$ Erick Guerra, "Planning for Cars That Drive Themselves," Journal of Planning Education and Research 36, no. 2 (2015): 210-24.

${ }^{14}$ Shaheen and Cohen, 2019.

153 Revolutions, UC Davis, “Glossary,” February 6, 2020, https://3rev.ucdavis.edu/glossary/.

${ }^{16}$ Urbanism Next-University of Oregon, “Mobility as a Service," 2020.

https://www.urbanismnext.org/technologies/mobility-as-a-service.

${ }^{17}$ Jana Sochor et al., "A Topological Approach to Mobility as a Service: A Proposed Tool for Understanding Requirements and Effects, and For Aiding the Integration of Societal Goals," Research in Transportation Business E' Management 27 (2018): 3.

${ }^{18}$ Solano Transportation Authority, "STA Announces Expansion of Lyft First/Last Mile Program in Response to COVID-19," March 24, 2020, https://sta.ca.gov/sta-announcesexpansion-of-lyft-first-last-mile-program-in-response-to-covid-19/.

${ }^{19}$ https://3rev.ucdavis.edu/glossary.

${ }^{20}$ Todd Litman, "Evaluating Carsharing Benefits," Transportation Research Record 1702, no. 1 (2000): 31 .

${ }^{21}$ Jeffrey B. Greenblatt and Susan Shaheen, "Automated Vehicles, On-Demand Mobility, and Environmental Impacts," Current Sustainable/Renewable Energy Reports 2, no. 3 (2015): 74-81.

223 Revolutions, UC Davis, 2020.

${ }^{23}$ Ibid. 
${ }^{24}$ Metro (Portland, OR), "Getting Around” (no date), https://www.oregonmetro.gov/toolsliving/getting-around/share-ride/vanpool.

${ }^{24}$ U.S. Department of Transportation, Federal Transit Administration, "Shared Mobility Definitions," February 28, 2020, https://www.transit.dot.gov/regulations-and-guidance/sharedmobility-definitions.

${ }^{25}$ Greenblatt and Shaheen, 2015.

${ }^{26}$ Patella et al., 2019.

${ }^{27}$ James H. Gawron et al., "Deep Decarbonization from Electrified Autonomous Taxi Fleets: Life Cycle Assessment and Case Study in Austin, TX," Transportation Research Part D: Transport and Environment 73 (2019): 130-141.

${ }^{28}$ Feigi Liu et al., "Can Autonomous Vehicle Reduce Greenhouse Gas Emissions? A CountryLevel Evaluation,” Energy Policy 132 (2019): 462-473.

${ }^{29}$ Christos Stogios et al., "Simulating Impacts of Automated Driving Behavior and Traffic Conditions on Vehicle Emissions," Transportation Research Part D: Transport and Environment 76 (2019): 176-192.

${ }^{30}$ Ibid.

${ }^{31}$ Liu et al., 2019.

${ }^{32}$ Daniel J. Fagnant and Kara M. Kockelman, "The Travel and Environmental Implications of Shared Autonomous Vehicles, Using Agent-Based Model Scenarios," Transportation Research Part C: Emerging Technologies 40 (2014): 1-13.

${ }^{33}$ Ibid.

${ }^{34}$ Wenwen Zhang, Subhrajit Guhathakurtab, and Elias B. Khalilc, "The Impact of Private Autonomous Vehicles on Vehicle Ownership and Unoccupied VMT Generation," Transportation Research Part C 90 (2018): 156-165.

${ }^{35}$ Greenblatt and Shaheen, 2015; Jeff McMahon, "How Car Sharing Can Save the World from The Autonomous-Vehicle Robot Apocalypse,” Forbes, March 18, 2018, https://www.forbes.com/sites/jeffmcmahon/2018/03/18/how-car-sharing-companies-can-savethe-world-from-the-autonomous-vehicle-robot-apocalypse/\#44bfad034fab.

${ }^{36}$ Gawron et al., 2019, p. 131.

${ }^{37}$ Alejandro Tirachini, "Ride-Hailing, Travel Behaviour and Sustainable Mobility: An International Review," Transportation 47 (2019): 1-37. 
${ }^{38}$ McMahon, 2018; Lia Catanneo, “Autonomous Vehicle Policy Must Consider Climate Impacts," Center for American Progress, June 12, 2018, https:/www.americanprogress.org/issues/green/news/2018/06/12/451993/autonomous-vehiclepolicy-must-consider-climate-impacts/.

${ }^{39}$ Jiyeon Jung and Yoonmo Koo, "Analyzing the Effects of Car Sharing Services on the Reduction of Greenhouse Gas (GHG) Emissions,” Sustainability 10 (2018): 539-556.

${ }^{40}$ Nikita Pavlenko, Peter Slowik, and Nic Lutsey, "When Does Electrifying Shared Mobility Make Economic Sense?" The International Council on Clean Transportation (2019), https://heicct.org/sites/default/files/publications/Electric_shared_mobility_20190108.pdf.

${ }^{41}$ Gordon S. Bauer et al., "Electrifying Urban Ridesourcing Fleets at No Added Cost Through Efficient Use of Charging Infrastructure," Transportation Research Part C: Emerging Technologies 105 (2019): 385-404.

${ }^{42}$ Peter Fox-Penner, Will Gorman, and Jennifer Hatch, "Long-Term US Transportation Electricity Use Considering the Effect of Autonomous-Vehicles: Estimates \& Policy Observations," Energy Policy 122 (2018): 203-213. https://doi.org/10.1016/j.enpol.2018.07.033.

${ }^{43}$ Patella et al., 2019.

${ }^{44}$ Erick C. Jones and Benjamin D. Leibowicz, "Contributions of Shared Autonomous Vehicles to Climate Change Mitigation," Transportation Research Part D: Transport and Environment 72 (2019): 279-298.

${ }^{45}$ Morteza Taiebat et al., "A Review on Energy, Environmental, and Sustainability Implications of Connected and Automated Vehicles," Environmental Science and Technology 52 (2018): 11449-11465.

${ }^{46}$ Ran Tu et al., "Quantifying the Impacts of Dynamic Control in Connected and Automated Vehicles on Greenhouse Gas Emissions and Urban NO2 Concentrations," Transportation Research Part D: Transport and Environment 73 (2019): 142-151.

${ }^{47}$ Tim Teubner and Christoph M. Flath, "The Economics of Multi-Hop Ride Sharing," Business E' Information Systems Engineering 57, no. 5 (2015): 311-324.

${ }^{48}$ Jonn Axsen and Benjamin K. Sovacool, "The Roles of Users in Electric, Shared and Automated Mobility Transitions," Transportation Research Part D: Transport and Environment 71 (2019): 1-21 p. 2.

${ }^{49}$ Ibid.

${ }^{50}$ Jones and Leibowicz, 2019; Harper et al., 2016. 
${ }^{51}$ Kopelias et al., 2020.

52 Zhang, Guhathakurtab, and Khalilc, 2018.

${ }^{53}$ Mark Golden, “Are Driverless Cars Bad for the Environment?” Stanford Earth, June 27, 2018, https://earth.stanford.edu/news/are-driverless-cars-bad-environment\#gs.mmhkfc.

${ }^{54}$ Thomopoulos and Givoni, 2015, p. 14.

${ }^{55}$ Clayton Lane, "PhillyCarShare: First-Year Social and Mobility Impacts of Carsharing in Philadelphia, Pennsylvania," Transportation Research Record 1927 (2005): 158-166.

56 Tirachini, 2019.

${ }^{57}$ Baiba Pudāne et al., "How Will Automated Vehicles Shape Users' Daily Activities? Insights from Focus Groups with Commuters in the Netherlands," Transportation Research Part D: Transport and Environment 71 (2019): 222-235.

58 Avigail Ferdman, "Corporate Ownership of Automated Vehicles: Discussing Potential Negative Externalities,” Transport Reviews 40, no. 1 (2020): 99.

${ }^{59}$ Adam Cohen and Susan Shaheen, Planning for Shared Mobility - PAS Report 583 (American Planning Association, 2018).

${ }^{60}$ Susan A. Shaheen, Mark A. Mallery, and Karla J. Kingsley, "Personal Vehicle Sharing Services in North America," Transportation Business E Management 3 (2012): 71-81.

${ }^{61}$ Anne Brown, "Redefining Car Access: Ride-Hail Travel and Use in Los Angeles," Journal of the American Planning Association 85, no. 2 (2019): 83-95.

${ }^{62}$ Giovanni Circella, Chris Ganson, and Caroline Rodier, Keeping Vehicle Use and Greenhouse Gas Emissions in Check in a Driverless Vehicle World (UC Davis - Institute of Transportation Studies, 2017).

${ }^{63}$ Ashly Z. Hand, "Redefining Urban Mobility: Four Ways Shared Autonomous Vehicles Will Reshape Our Cities,” Real Estate Issues, Special Issue - Global Real Estate (Spring 2017), https://www.cre.org/real-estate-issues/redefining-urban-mobility-four-ways-sharedautonomous-vehicles-will-reshape-cities/.

${ }^{64}$ Sara Friedman, "States Embrace Benefits of Autonomous Vehicles," GCN, January 25, 2018, https:/gcn.com/articles/2018/01/25/state-autonomous-vehicles.aspx; Dave Nyczepir, "City Leaders Envision Future with Driverless Cars,” Route Fifty, June 4, 2018, https:/www.routefifty.com/smart-cities/2018/05/san-francisco-city-attorney-herrerasubpoenas-uber-lyft/148571/. 
${ }^{65}$ Joseph M. Giglio and Charles Chieppo, "Self-Driving Cars Could Make Commuter Rail Obsolete," Boston Globe, February 15, 2019, https://www.bostonglobe.com/opinion/2019/02/15/self-driving-cars-could-make-commuterrail-obsolete/QUtzN71fCJBqx01Ra71tKP/story.html.

${ }^{66}$ John Niles, Automated Vehicles Have Arrived: What's a Transit Agency to Do? (Mineta Transportation Institute, 2019).

${ }^{67}$ Daniel Sperling, Austin Brown, and Mollie D'Agostino, "How Ride-Hailing Could Improve Public Transportation Instead of Undercutting It," The Conversation, July 5, 2018, http://theconversation.com/how-ride-hailing-could-improve-public-transportation-instead-ofundercutting-it-96453.

${ }^{68}$ Giglio and Chieppo, 2019.

${ }^{69}$ Ibid.; Rico Krueger, Taha H. Rashidi, and John M. Rose, "Preferences for Shared Autonomous Vehicles," Transportation Research Part C: Emerging Technologies 69 (2016): 343355 .

${ }^{70}$ Golden, 2018; Sperling, Brown, and D’Agostino, 2018.

${ }^{71}$ Sperling, Brown, and D'Agostino, 2018.

${ }^{72}$ Ibid.

${ }^{73}$ Shared-Use Mobility Center, Shared Mobility and the Transformation of Public Transit (American Public Transportation Association, 2016); Sperling, Brown, and D'Agostino, 2018.

${ }^{74}$ Shared-Use Mobility Center, 2016.

${ }^{75}$ Sperling, Brown, and D'Agostino, 2018.

${ }^{76}$ Ibid.

${ }^{77}$ Sudmant et al., "Towards Sustainable Mobility and Improved Public Health: Les-sons from Bike Sharing in Shanghai, China" (Coalition for Urban Transitions, 2020), https://urbantransitions.global/en/publication/china-frontrunners/.

${ }^{78}$ Litman, 2017.

${ }^{79}$ Kelly Fleming and Mark Singer, "Energy Implications of Current Travel and the Adoption of Automated Vehicles" (National Renewable Energy Laboratory, April 2019), https://www.nrel.gov/docs/fy19osti/72675.pdf.

${ }^{80}$ Krueger, Rashidi, and Rose, 2016. 
${ }^{81}$ Fleming and Singer, 2019.

${ }^{82}$ Krueger, Rashidi, and Rose, 2016.

${ }^{83}$ Kevin DeGood and Andrew Schwartz, "Can New Transportation Technologies Improve Equity and Access to Opportunity?” (Center for American Progress, April 27, 2016), https://www.americanprogress.org/issues/economy/reports/2016/04/27/135425/can-newtransportation-technologies-improve-equity-and-access-to-opportunity/.

${ }^{84}$ Sperling, Brown, and D’Agostino, 2018.

${ }^{85}$ Ibid.

${ }^{86}$ Friedman, 2018; Jacques Leslie, "Will Self-Driving Cars Usher in a Transportation Utopia or Dystopia?” Yale Environment 360, January 8, 2018, https://e360.yale.edu/features/will-selfdriving-cars-usher-in-a-transportation-utopia-or-dystopia; Sperling, Brown, and D’Agostino, 2018; Harper et al., 2016.

${ }^{87}$ Harper et al., 2016.

${ }^{88}$ Hana Creger, Joel Espino, and Alvaro S. Sanchez, "Autonomous Vehicle Heaven or Hell" (The Greenlining Institute, January 2019), http://greenlining.org/wpcontent/uploads/2019/01/R4_AutonomousVehiclesReportSingle_2019_2.pdf.

${ }^{89}$ ICLEI USA, "Five Milestones for Emissions Management" (2020 ICLEI USA—Local Governments for Sustainability, 2020, http://icleiusa.org/programs/emissions-management/5milestones/.

${ }^{90}$ Greenblatt and Shaheen, 2015.

${ }^{91}$ Bulkeley, Edwards, and Fuller, 2014.

${ }^{92}$ Brown, 2019. 


\section{Bibliography}

3 Revolutions, UC Davis. "Glossary.” February 6, 2020. https://3rev.ucdavis.edu/glossary.

Alessandrini, Adriano, et al. "Automated Vehicles and the Rethinking of Mobility and Cities.” Transportation Research Procedia 5 (2015): 145-60. doi:10.1016/j.trpro.2015.01.002

Alexander, Lauren P., and Marta C. González. "Assessing the Impact of Real-Time Ridesharing on Urban Traffic Using Mobile Phone Data.” Proc. UrbComp (2015): 1-9. http://humnetlab.berkeley.edu/wp-content/uploads/2020/02/Real-timeRidesharing_Alexander.pdf.

Amatuni, Levon, et al. "Does Car Sharing Reduce Greenhouse Gas Emissions? Life Cycle Assessment of the Modal Shift and Lifetime Shift Rebound Effects." arXiv.org, 2019. http://arxiv.org/abs/1910.11570.

Axsen, Jonn, and Benjamin K. Sovacool. "The Roles of Users in Electric, Shared and Automated Mobility Transitions." Transportation Research Part D: Transport and Environment 71 (2019): 1-21. https://doi.org/10.1016/j.trd.2019.02.012.

Bauer, Gordon S., et al. "Electrifying Urban Ridesourcing Fleets at No Added Cost Through Efficient Use of Charging Infrastructure." Transportation Research Part C: Emerging Technologies 105 (2019): 385-404. https://doi.org/10.1016/j.trc.2019.05.041.

Boswell, Michael R., Adrienne I. Greve, and Tammy L. Seale. Local Climate Action Planning. Washington, D.C., Island Press, 2012.

Brown, Anne. "Redefining Car Access: Ride-Hail Travel and Use in Los Angeles." Journal of the American Planning Association 85, no. 2 (2019): 83-95. https://doi.org/10.1080/01944363.2019.1603761.

Brown, Austin, Jeffrey Gonder, and Brittany Repac. "An Analysis of Possible Energy Impacts of Automated Vehicle.” In Road Vehicle Automation, eds. Gereon Meyer and Sven Beiker, pp. 137-153. Springer, 2014. doi: 10.1007/978-3-319-05990-7.

Bulkeley, Harriet, Gareth A.S. Edwards, and Sara Fuller. "Contesting Climate Justice in the City: Examining Politics and Practice in Urban Climate Change Experiments." Global Environmental Change 25 (2014): 31-40.

Cambridge Systematics. Moving Cooler: An Analysis of Transportation Strategies for Reducing Greenhouse Gas Emissions. Washington, DC: Urban Land Institute, 2009 
Catanneo, Lia. "Autonomous Vehicle Policy Must Consider Climate Impacts." Center for A Observations." Energy Policy 122 (2018): 203-213.

American Progress, Jime 1/2, 2018.2018.07.033.

https:\%/www.anpericanprogress.org/1ssues/green/news/2018/06/12/451993/autonomousvehicle-policy-must-consider-climate-impacts/.

Chan, Nelson D., and Susan A. Shaheen. "Ridesharing in North America: Past, Present, and Future.” Transport Reviews 32, no. 1 (2012): 93-112.

Circella, Giovanni, Chris Ganson, and Caroline Rodier. Keeping Vehicle Use and Greenhouse Gas Emissions in Check in a Driverless Vebicle World. UC Davis - Institute of Transportation Studies, 2017. doi: 10.7922/G2F18WN0

Cohen, Adam, and Susan Shaheen. Planning for Shared Mobility (PAS Report 583). American Planning Association, 2018. doi: 10.7922/G2NV9GDD

Creger, Hana, Joel Espino, and Alvaro S. Sanchez. “Autonomous Vehicle Heaven or Hell.” The Greenlining Institute, January 2019. http://greenlining.org/wpcontent/uploads/2019/01/R4_AutonomousVehiclesReportSingle_2019_2.pdf.

DeGood, Kevin, and Andrew Schwartz. "Can New Transportation Technologies Improve Equity and Access to Opportunity?" Center for American Progress, April 27, 2016. https://www.americanprogress.org/issues/economy/reports/2016/04/27/135425/cannew-transportation-technologies-improve-equity-and-access-to-opportunity/.

Fagnant, Daniel J., and Kara M. Kockelman. "The Travel and Environmental Implications of Shared Autonomous Vehicles, Using Agent-Based Model Scenarios.” Transportation Research Part C: Emerging Technologies 40 (2014): 1-13. https://doi.org/10.1016/j.trc.2013.12.001.

Ferdman, Avigail. "Corporate Ownership of Automated Vehicles: Discussing Potential Negative Externalities." Transport Revierws 40, no. 1 (2020): 95-113. https://doi.org/10.1080/01441647.2019.1687606.

Fleming, Kelly, and Mark Singer. "Energy Implications of Current Travel and the Adoption of Automated Vehicles.” National Renewable Energy Laboratory, April 2019. https://www.nrel.gov/docs/fy19osti/72675.pdf.

Fox-Penner, Peter, Will Gorman, and Jennifer Hatch. "Long-Term US Transportation Electricity Use Considering the Effect of Autonomous-Vehicles: Estimates \& Policy Observations." Energy Policy 122 (2018): 203-213. https://doi.org/10.1016/j.enpol.2018.07.033. 
Friedman, Sara. "States Embrace Benefits of Autonomous Vehicles." GCN, January 25, 2018. https://gcn.com/articles/2018/01/25/state-autonomous-vehicles.aspx.

Gawron, James H., et al. "Deep Decarbonization from Electrified Autonomous Taxi Fleets: Life Cycle Assessment and Case Study in Austin, TX." Transportation Research Part D: Transport and Environment 73 (2019): 130-141. https://doi.org/10.1016/j.trd.2019.06.007.

Giglio, Joseph M., and Charles Chieppo. "Self-Driving Cars Could Make Commuter Rail Obsolete." Boston Globe, February 15, 2019. https://www.bostonglobe.com/opinion/2019/02/15/self-driving-cars-could-makecommuter-rail-obsolete/QUtzN71fCJBqx01Ra71tKP/story.html

Golden, Mark. “Are Driverless Cars Bad for the Environment?” Stanford Earth, June 27, 2018. https://earth.stanford.edu/news/are-driverless-cars-bad-environment\#gs.mmhkfc.

Greenblatt, Jeffery B., and Samveg Saxena. "Autonomous Taxis could Greatly Reduce Greenhouse-Gas Emissions of US Light-Duty Vehicles.” Nature Climate Change 5, no. 9 (2015): 860. https://doi.org/10.1038/nclimate2685.

Greenblatt, Jeffery B., and Susan Shaheen. "Automated Vehicles, On-Demand Mobility, and Environmental Impacts.” Current Sustainable/Renewable Energy Reports 2, no. 3 (2015): 74-81. https://doi.org/10.1007/s40518-015-0038-5.

Guerra, Erick. "Planning for Cars That Drive Themselves." Journal of Planning Education and Research 36, no. 2 (2015): 210-24. doi:10.1177/0739456x15613591.

Hand, Ashley Z. "Redefining Urban Mobility: Four Ways Shared Autonomous Vehicles Will Reshape Our Cities.” Real Estate Issues, Special Issue - Global Real Estate (Spring 2017). https://www.cre.org/real-estate-issues/redefining-urban-mobility-four-ways-sharedautonomous-vehicles-will-reshape-cities/.

Harper, Corey D., et al. "Estimating Potential Increases in Travel with Autonomous Vehicles for the Non-driving, Elderly and People with Travel-Restrictive Medical Conditions." Transportation Research Part C: Emerging Technologies 72 (2016): 1-9. https://doi.org/10.1016/j.trc.2016.09.003.

ICLEI USA. “Five Milestones for Emissions Management." 2020. http://icleiusa.org/programs/emissions-management/5-milestones/. 
Jones, Erick C., and Benjamin D. Leibowicz. "Contributions of Shared Autonomous Vehicles to Climate Change Mitigation." Transportation Research Part D: Transport and Environment 72 (2019): 279-298. https://doi.org/10.1016/j.trd.2019.05.005.

Jung, Jiyeon, and Yoonmo Koo. "Analyzing the Effects of Car Sharing Services on the Reduction of Greenhouse Gas (GHG) Emissions.” Sustainability 10 (2018): 539 - 556. https://doi.org/10.3390/su10020539.

Kopelias, Pantelis, et al. "Connected \& Autonomous Vehicles-Environmental Impacts-A Review." Science of the Total Environment 712 (2020): 135237. https://doi.org/10.1016/j.scitotenv.2019.135237.

Krueger, Rico, Taha H. Rashidi, and John M. Rose. "Preferences for Shared Autonomous Vehicles." Transportation Research Part C: Emerging Technologies 69 (2016): 343-355. https://doi.org/10.1016/j.trc.2016.06.015.

Lane, Clayton. "PhillyCarShare: First-Year Social and Mobility Impacts of Carsharing in Philadelphia, Pennsylvania." Transportation Research Record: Journal of the Transportation Research Board 1927 (2005): 158-166. https://doi.org/10.1177/0361198105192700118.

Leslie, Jacques. "Will Self-Driving Cars Usher in a Transportation Utopia or Dystopia?" Yale Environment 360, January 8, 2018. https://e360.yale.edu/features/will-self-driving-carsusher-in-a-transportation-utopia-or-dystopia

Liebman, Michael. "What Mobility as a Service (MaaS) Means for the Transportation Industry." GreenBiz, June 11, 2018. Accessed June 15, 2018. https://www.greenbiz.com/article/what-mobility-service-maas-means-transportationindustry.

Litman, Todd. Autonomous Vebicle Implementation Predictions. Victoria Transport Policy Institute, 2017.

Litman, Todd. "Evaluating Carsharing Benefits." Transportation Research Record 1702, no. 1 (2000): 31-35. doi: 10.3141/1702-04.

Liu, Feiqi, et al. "Can Autonomous Vehicle Reduce Greenhouse Gas Emissions? A CountryLevel Evaluation.” Energy Policy 132 (2019): 462-473. https://doi.org/10.1016/j.enpol.2019.06.013.

McKendry, Corina. "Cities and the Challenge of Mltiscalar Climate Justice: Climate Governance and Social Equity in Chicago, Birmingham, and Vancouver." Local Environment 21, no. 11 (2016): 1354-1371. https://doi.org/10.1080/13549839.2015.1116064. 
McMahon, Jeff. "How Car Sharing Can Save The World from The Autonomous-Vehicle Robot Apocalypse.” Forbes, March 18, 2018.

https://www.forbes.com/sites/jeffmcmahon/2018/03/18/how-car-sharing-companiescan-save-the-world-from-the-autonomous-vehicle-robot-apocalypse/\#44bfad034fab.

Metro (Portland, OR). “Getting Around.” No date. https://www.oregonmetro.gov/toolsliving/getting-around/share-ride/vanpool.

Morrow, William R., et al. "Key Factors Influencing Autonomous Vehicles' Energy and Environmental Outcome." In Road Vebicle Automation, eds. Gereon Meyer and Sven Beiker. pp. 127-135. Springer, 2014. https://doi.org/10.1007/978-3-319-05990-7_12.

National Research Council. Transitions to Alternative Vebicles and Fuels. National Academies Press, 2013.

Niles, John. Automated Vehicles Have Arrived: What's a Transit Agency to Do? San José: Mineta Transportation Institute, 2019.

Nyczepir, Dave. "City Leaders Envision Future with Driverless Cars.” Route Fifty, June 4, 2018. https://www.routefifty.com/smart-cities/2018/05/san-francisco-city-attorney-herrerasubpoenas-uber-lyft/148571/.

Patella, S. M., et al. "Carbon Footprint of Autonomous Vehicles at the Urban Mobility System Level: A Traffic Simulation-Based Approach.” Transportation Research Part D: Transport and Environment 74 (2019): 189-200. https://doi.org/10.1016/j.trd.2019.08.007.

Pavlenko, Nikita, Peter Slowik, and Nic Lutsey. "When Does Electrifying Shared Mobility Make Economic Sense?" The International Council on Clean Transportation (2019). https://theicct.org/sites/default/files/publications/Electric_shared_mobility_20190108.pd f.

Pudāne, Baiba, et al. "How Will Automated Vehicles Shape Users' Daily Activities? Insights from Focus Groups with Commuters in the Netherlands." Transportation Research Part D: Transport and Environment 71 (2019): 222-235. https://doi.org/10.1016/j.trd.2018.11.014.

Pyzyk, Katie. “Lyft, Phoenix Partner for 'First Mile Last Mile' Rides to Bus Stops.” Smart Cities Dive, October 23, 2017. https://www.smartcitiesdive.com/news/lyft-phoenix-partnerfor-first-mile-last-mile-rides-to-bus-stops/507791/.

SAE International. Press release, 2018. https:/www.sae.org/news/press-room/2018/12/saeinternational-releases-updated-visual-chart-for-its-\%E2\%80\% Clevels-of-drivingautomation\%E2\%80\%9D-standard-for-self-driving-vehicles. 
Shaheen, Susan, and Adam Cohen. "Shared Ride Services in North America: Definitions, Impacts, and the Future of Pooling." Transport Reviews 39, no. 4 (2019): 427-442. https://doi.org/10.1080/01441647.2018.1497728.

Shaheen, Susan A., Mark A. Mallery, and Karla J. Kingsley. "Personal Vehicle Sharing Services in North America." Transportation Business E' Management 3 (2012): 71-81. https://doi.org/10.1016/j.rtbm.2012.04.005.

Shared-Use Mobility Center. Shared Mobility and the Transformation of Public Transit. American Public Transportation Association, 2016.

Sochor, Jana, et al. "A Topological Approach to Mobility as a Service: A Proposed Tool for Understanding Requirements and Effects, and For Aiding the Integration of Societal Goals." Research in Transportation Business E于 Management 27 (2018): 3-14. https://doi.org/10.1016/j.rtbm.2018.12.003.

Solano Transportation Authority. "STA Announces Expansion of Lyft First/Last Mile Program in Response to COVID-19." March 24, 2020. https://sta.ca.gov/sta-announcesexpansion-of-lyft-first-last-mile-program-in-response-to-covid-19/.

Sperling, Daniel, Austin Brown, and Mollie D’Agostino. "How Ride-Hailing Could Improve Public Transportation Instead of Undercutting It." The Conversation, July 5, 2018. http://theconversation.com/how-ride-hailing-could-improve-public-transportationinstead-of-undercutting-it-96453.

Stogios, Christos, et al. "Simulating Impacts of Automated Driving Behavior and Traffic Conditions on Vehicle Emissions." Transportation Research Part D: Transport and Environment 76 (2019): 176-192. https://doi.org/10.1016/j.trd.2019.09.020.

Sudmant, A., et al. "Towards Sustainable Mobility and Improved Public Health: Lessons from Bike Sharing in Shanghai, China." Coalition for Urban Transitions, 2020. https:/urbantransitions.global/en/publication/china-frontrunners/.

Sui, Yi, et al. "GPS Data in Urban Online Ride-Hailing: A Comparative Analysis on Fuel Consumption and Emissions." Journal of Cleaner Production 227 (2019): 495-505. https://doi.org/10.1016/j.jclepro.2019.04.159.

Systematics, Cambridge. Moving Cooler: An Analysis of Transportation Strategies for Reducing Greenhouse Gas Emissions. Washington, DC: Urban Land Institute, 2009.

Taiebat, Morteza, et al. "A Review on Energy, Environmental, and Sustainability Implications of Connected and Automated Vehicles." Environmental Science and Technology 52 (2018): 11449-11465. https://doi.org/10.1021/acs.est.8b00127. 
Teubner, Timm, and Christoph M. Flath. "The Economics of Multi-Hop Ride Sharing." Business E Information Systems Engineering 57, no. 5 (2015): 311-324. https://doi.org/10.1007/s12599-015-0396-y.

Thomopoulos, Nikolas, and Moshe Givoni. "The Autonomous Car-A Blessing or a Curse for the Future of Low Carbon Mobility? An Exploration of Likely vs. Desirable Outcomes." European Journal of Futures Research 3, no. 1 (2015): 14. https://doi.org/10.1007/s40309-015-0071-z.

Tirachini, Alejandro. "Ride-Hailing, Travel Behaviour and Sustainable Mobility: An International Review.” Transportation 47 (2019): 1-37. https://doi.org/10.1007/s11116019-10070-2.

Tu, Ran, et al. "Quantifying the Impacts of Dynamic Control in Connected and Automated Vehicles on Greenhouse Gas Emissions and Urban NO2 Concentrations." Transportation Research Part D: Transport and Environment 73 (2019): 142-151. https://doi.org/10.1016/j.trd.2019.06.008.

Urbanism Next-University of Oregon. "Mobility as a Service." 2020. https://www.urbanismnext.org/technologies/mobility-as-a-service.

Urbanism Next-University of Oregon. "Policy Brief - AVs in the Pacific Northwest: Reducing Greenhouse Gas Emissions in a Time of Automation.” 2019. https://www.urbanismnext.org/resources/policy-brief-avs-in-the-pacific-northwestreducing-greenhouse-gas-emissions-in-a-time-of-automation.

"Micromobility." 2020. https://www.urbanismnext.org/technologies/micromobility.

U.S. Department of Transportation, Federal Transit Administration. "Shared Mobility Definitions.” February 28, 2020. https://www.transit.dot.gov/regulations-andguidance/shared-mobility-definitions.

Wadud, Zia, Don MacKenzie, and Paul Leiby. "Help or Hindrance? The Travel, Energy and Carbon Impacts of Highly Automated Vehicles.” Transportation Research Part A: Policy and Practice 86 (2016): 1-18. https://doi.org/10.1016/j.tra.2015.12.001.

Zhang, Wenwen, Subhrajit Guhathakurtab, and Elias B. Khalilc. "The Impact of Private Autonomous Vehicles on Vehicle Ownership and Unoccupied VMT Generation." Transportation Research Part C 90 (2018): 156-165. https://doi.org/10.1016/j.trc.2018.03.005. 
Zhang, Wenwen, et al. "Exploring the Impact of Shared Autonomous Vehicles on Urban Parking Demand: An Agent-Based Simulation Approach." Sustainable Cities and Society 19 (2015): 34-45. https://doi.org/10.1016/j.scs.2015.07.006. 


\section{About the Authors}

\section{Serena Alexander, PhD}

Serena Alexander is an Assistant Professor of Urban and Regional Planning at San José State University. Her primary research interests are in the areas of environmental planning, climate action, and land-use and transportation planning. Before joining the SJSU faculty, Dr. Alexander conducted community economic development and environmental policy research at the Center for Economic Development and the Great Lakes Environmental Finance Center at Cleveland State University, where she also received her doctorate in Urban Studies (Specialization in Urban Policy and Development). She holds master's degrees in Urban and Regional Planning from California State Polytechnic University, Pomona, and Architecture from Azad University of Tehran.

\section{Asha Weinstein Agrawal, PhD}

Dr. Agrawal is Professor of Urban and Regional Planning at San José State University. Her research is guided by a commitment to the principles of sustainability and equity: what planning and policy tools can communities adopt to encourage environmentally-friendly travel and improve accessibility for people struggling with poverty or other disadvantages? She has explored this question most deeply through two substantive areas, transportation finance policy and the travel behavior of pedestrians, cyclists, and transit riders. She has a BA from Harvard University in Folklore and Mythology, an MSc from the London School of Economics and Political Science in Urban and Regional Planning, and a $\mathrm{PhD}$ from the University of California, Berkeley, in City and Regional Planning.

\section{Benjamin Y. Clark, PhD}

Dr. Clark is Associate Professor in the School of Planning, Public Policy and Management and the Co-Director of the Institute for Policy Research and Engagement at the University of Oregon in Eugene, Oregon, USA. His research and external engagement are largely focused on local government management. His scholarship examines how technology can be used to improve city management (smart city technology) and how cities need to be planning financially and managerially for future innovations (smart cities and autonomous vehicles). Before his move into academia, he worked as a public servant at the local, federal, and international levels. 


\section{Hon. Norman Y. Mineta}

\section{MTI BOARD OF TRUSTEES}

Founder, Honorable Norman

Mineta*

Secretary (ret.),

US Department of Transportation

Chair,

Abbas Mohaddes

President \& COO

Econolite Group Inc.

Vice Chair,

Will Kempton

Executive Director

Sacramento Transportation Authority

Executive Director,

Karen Philbrick, PhD*

Mineta Transportation Institute

San José State University

Winsome Bowen

Chief Regional Transportation

Strategy

Facebook

David Castagnetti

Co-Founder

Mehlman Castagnetti

Rosen \&Thomas

\section{Maria Cino}

Vice President

America \& U.S. Government

Relations Hewlett-Packard

Enterprise

\author{
Grace Crunican** \\ Owner \\ Crunican LLC
}

Donna DeMartino

Managing Director

Los Angeles-San Diego-San Luis

Obispo Rail Corridor Agency

Nuria Fernandez**

General Manager \& CEO

Santa Clara Valley Transportation

Authority (VTA)

\section{John Flaherty}

Senior Fellow

Silicon Valley American

Leadership Form

William Flynn *

President \& CEO

Amtrak

Rose Guilbault

Board Member

Peninsula Corridor

Joint Powers Board

Ian Jefferies*

President \& CEO

Association of American

Railroads
Diane Woodend Jones

Principal \& Chair of Board

Lea + Elliott, Inc.

David S. Kim*

Secretary

California State Transportation

Agency (CALSTA)

Therese McMillan

Executive Director

Metropolitan Transportation

Commission (MTC)

Bradley Mims

President \& CEO

Conference of Minority

Transportation Officials

(COMTO)

Jeff Morales

Managing Principal

InfraStrategies, LLC

Dan Moshavi, PhD*

Dean, Lucas College and Graduate

School of Business

San José State University

Toks Omishakin*

Director

California Department of

Transportation (Caltrans)
Takayoshi Oshima

Chairman \& CEO

Allied Telesis, Inc.

Paul Skoutelas*

President \& CEO

American Public Transportation

Association (APTA)

Beverley Swaim-Staley

President

Union Station Redevelopment

Corporation

Jim Tymon*

Executive Director

American Association of

State Highway and

Transportation Officials

(AASHTO)

Larry Willis*

President

Transportation Trades

Dept.,AFL-CIO

* = Ex-Officio

${ }^{* *}=$ Past Chair, Board of Trustees

\section{Directors}

Karen Philbrick, PhD

Executive Director

Hilary Nixon, PhD

Deputy Executive Director

Asha Weinstein Agrawal, PhD

Education Director

National Transportation Finance

Center Director

\section{Brian Michael Jenkins}

National Transportation Security

Center Director

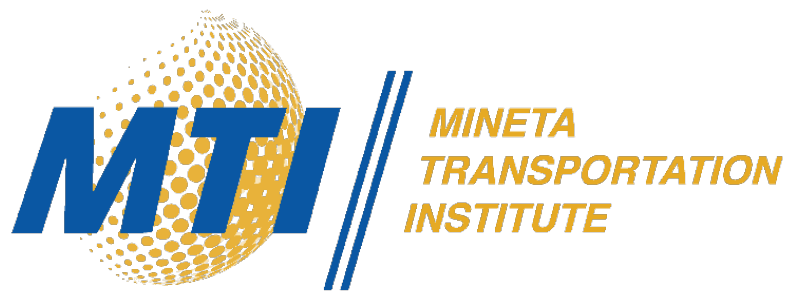

